\title{
THE EFFECTS OF CENTRIFUGAL FORCE UPON THE EGGS OF SOME CHRYSOMELID BEETLES ${ }^{1}$
}

$\mathbf{B Y}$

R. W. HEGNER

With Twenty-Four Figures

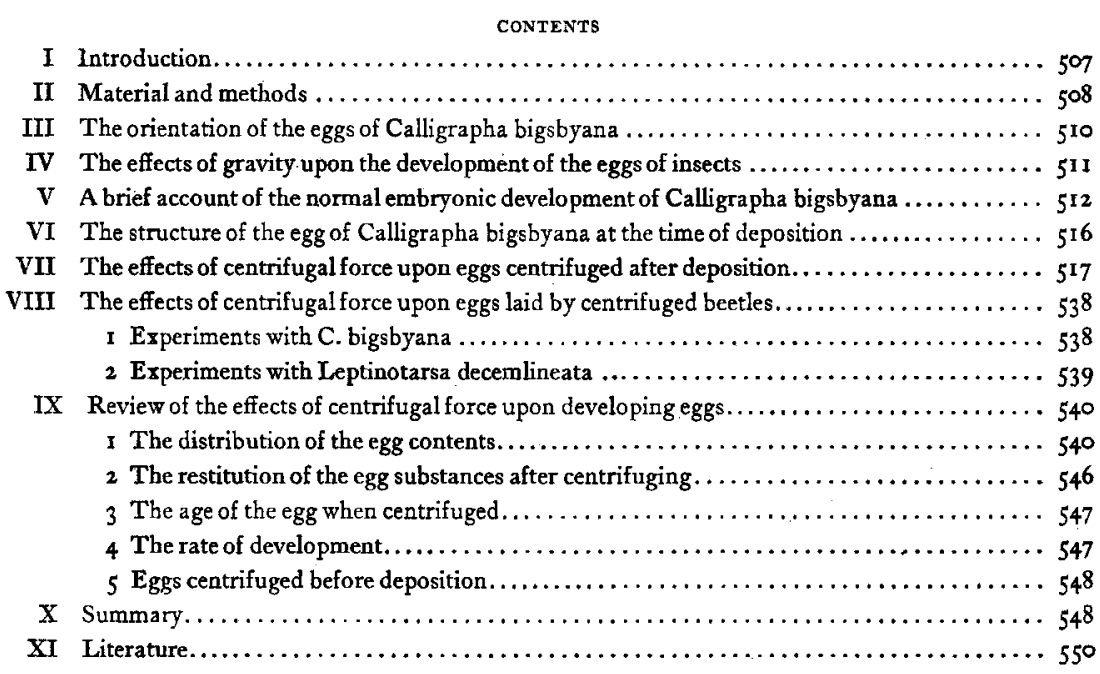

\section{INTRODUCTION}

It has been found that insect eggs are definitely oriented within the ovaries and the exact position of the future embryo seems to be determined already at this early period. This fact has led many embryologists to believe that the eggs of insects are very highly organized. If this is true a redistribution of the contents of the egg would have a profound effect upon the development of the embryo. In order to obtain a rearrangement of material a centrifugal machine was used successfully, as is shown by the experiments described in Part VII of this paper.

1 Contributions from the Zoölogical Laboratory of the University of Michigan. No. I25.

The Journal of Experimental Zoölogy, vol. vi, No. 4- 
During the course of the study of the germ-cells in some chrysomelid beetles ${ }^{2}$ a disc-shaped mass of granules (Fig. 9, g.c.d) was discovered in the freshly laid eggs suspended in the peripheral layer of cytoplasm at the posterior end. I have called this structure the "pole-disc." These granules are taken up by the germcells in the course of their migration and apparently determine the character of these cells; on this account I have called them "germcell determinants" (Hegner '08 b). It was hoped by means of centrifugal force to scatter the granules of the pole-disc and obtain an embryo either without germ-cells or with germ-cells in various parts of the body. It was also thought possible that the pole-disc might move as a whole and, becoming massed in some other region of the egg, might influence at this point cells which would ordinarily become body-cells. As will be seen later some data were secured but not enough to warrant any definite conclusions.

So far as I have been able to learn from the literature no experiments with centrifugal force upon the eggs of insects have ever been performed successfully and in only one case has any arthropod egg been tested in a centrifugal machine (Lyon 'o7). Lyon merely says: "The ovarian eggs of the common garden spider could be separated by one minute's centrifugalizing into two layers" (p. I69).

The experiments described below were begun at the University of Wisconsin in the spring of 1908 and were continued at the Marine Biological Laboratory at Woods Holl, Mass., where I occupied a room subscribed for by the Wistar Institute of Anatomy and Biology. The material was further studied at the Zoölogical Laboratory of the University of Michigan.

\section{MATERIAL AND METHODS}

During the course of this work eggs of the following beetles were used for experiments: Calligrapha multipunctata, C. bigsbyana, C. lunata, Leptinotarsa decemlineata and Lema trilineata. The posterior ends of these eggs are fastened to the leaf on which they

${ }^{2}$ The Origin and Early History of the Germ-Cells in Some Chrysomelid Beetles. Accepted for publication by the Journal of Morphology. 
are laid. In the case of Calligrapha multipunctata and C. bigsbyana the eggs can be definitely oriented as is explained in the next part of this paper. A number of beetles were kept in the laboratory and the eggs were marked on the anterior-ventral surface with a small spot of waterproof india ink. The exact time of deposition was recorded in all cases. The eggs are not always in the same stage of development at the time of laying, but all those in one batch are approximately in the same condition. When the eggs had developed to the desired point they were placed in small indentations in a block of paraffin. The entire block containing the eggs was then lowered to the bottom of a glass tube of an ordinary water-power centrifugal machine. The eggs were then $15 \mathrm{~cm}$. from the axis of rotation. The number of revolutions per minute was not accurately determined, but was probably between 1500 and 2000 , although in some cases (those described in experiments C. M. I and L. D. I and 2) a slower rate of speed was used ( 360 revolutions per minute). The eggs when taken from the centrifugal machine were left in the cavities in the paraffin block with the heavy end down until they were fixed. In previous work I found a modification of Petrunkewitsch's fluid the best for killing and fixing the eggs. This was used entirely for the centrifuged material, although control eggs were fixed in a number of the common mixtures. Eggs were stained in toto with Mayer's hremalum acidulated with 2 per cent of glacial acetic acid, or with alum cochineal. Sections were stained on the slide principally with hæmalum followed by Bordeaux red.

One difficulty in doing experimental work with the eggs of Calligrapha is that only a few are laid at one time (eight is the average number) and, as the conditions of the experiments frequently are responsible for the destruction of some of these, no series contains very many successive stages.

There are also causes for trouble in making preparations. In some instances the eggs stuck fast to the chorion at the outer end, where the contents had been strongly driven against it; the chorion could not be removed from these without injury to that part of the egg. After eggs have been centrifuged they are more difficult to section than before because the large deutoplasmic spheres collect 
at the end away from the axis of rotation and a breaking out is frequent in this region.

\section{THE ORIENTATION OF THE EGGS OF CALLIGRAPHA BIGSBYANA}

It has been known for more than twenty years that the eggs of insects are definitely oriented within the ovaries of the adults. Hallez in 1886 , finding this to be true of the ova of Hydrophilus and Locusta, expressed the fact in his "Loi de l'orientation de l'embryon chez les Insectes" as follows. "La cellule-oeuf possède la même orientation que l'organisme maternel qui l'a produit: elle a un pôle cèphalique et un pôle caudal, un côté droit et un côté gauche,
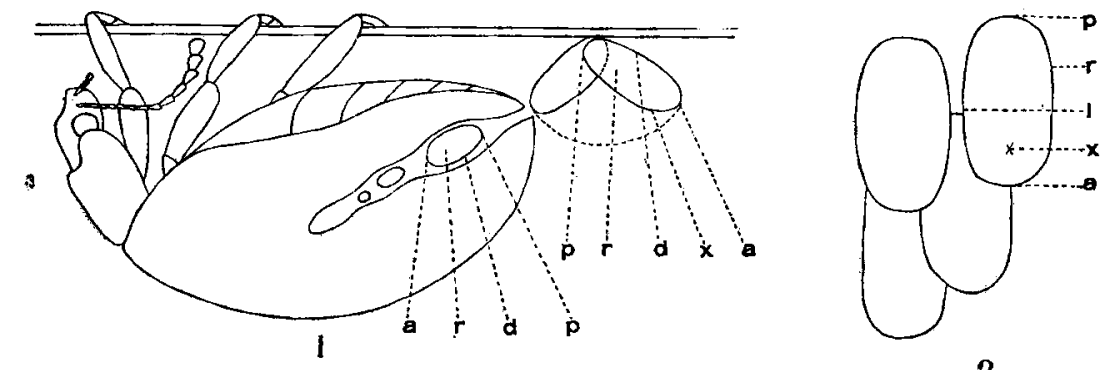

2.

Fig. I A diagrammatic drawing of $\mathrm{C}$. bigsbyana clinging to the under side of a willow leaf and showing the orientation of the egg in the ovarian tubule and after deposition.

Fig. 2 Four eggs of C. bigsbyana laid in two rows. $a_{.}=$anterior. $d_{0}=$ dorsal. $l_{.}=$left. $p_{0}=$ posterior. $r_{0}=$ right. $x_{.}=$anterior ventral surface where the spot of India ink was placed as a guide for orienting the eggs during the experiments.

une face dorsale et une face ventrale; et ces différentes faces de la cellule-oeuf coincident aux faces correspondantes de l'embryon."

No difficulty is experienced in distinguishing the anterior from the posterior end of the eggs of Chrysomelid beetles as it is always the posterior end which first emerges from the vagina. This end is fastened to the leaf on which the egg is laid and subsequently becomes the posterior end of the embryo, regardless of the position of the leaf. In only two species (Calligrapha multipunctata and C. bigsbyana) of the many Chrysomelid beetles examined could the right and left sides of the egg be accurately determined. The egg laying of these insects is as follows: "The beetle selects 
a leaf and clings to its under surface. The tip of the abdomen moves rhythmically up and down about fifteen times at intervals of a little less than one second. This results in the exudation of a drop of viscid, colorless fluid about one-third the transverse diameter of the egg. The egg is forced out a moment later and carries with it this drop of fluid by means of which it is fastened to the leaf. When the egg reaches the leaf it is pushed back away from the beetle (Fig. I), which then moves to one side and again begins the rhythmical movements which precede the laying of another egg. In this way eggs are laid in a double row as shown in the accompanying figure (Fig. 2), but frequently three or more may be laid in one row. The intervals between the layings of the individual eggs average one minute and twenty seconds" (Hegner 'o8 a). Two to nineteen eggs are laid at one time, the average number being eight. Fig. I indicates the orientation of the egg of C. bigsbyana lying in the ovary and also the final position after it has been laid.

\section{THE EFFECTS OF GRAVITY UPON THE DEVELOPMENT OF THE EGGS OF INSECTS}

That the position of the insect egg after laying has no influence upon the development of the embryo was proved by Wheeler (I889) in the case of Blatta. This author kept capsules from fourteen to twenty days in the following positions:

"I Resting with the lateral faces perpendicular and crista uppermost.

" 2 Resting on the crista with the lateral faces perpendicular.

"3 Resting on the left lateral face.

“4 Resting perpendicularly on the anterior end.

"5 Resting perpendicularly on the posterior end.

"In all these cases the eggs developed normally, without the slightest indication of displacement in position or alteration of shape in the embryo; whether they were forced to develop with their heads pointing up or down." The conclusion reached was that "the force of gravitation has no perceptible effect on the development of the eggs of Blatta 
Wheeler also proved that the antero-posterior differentiation of the embryo of Leptinotarsa decemlineata is not affected by changes in the position of the egg after laying, but is predetermined in the ovary.

During the course of my work with Calligrapha, eggswere taken as soon as laid and placed in every possible position. The embryos were found to be in no way affected by the orientation of the egg with respect to gravity.

The only exception to the rule that gravity has no influence upon the development of insects' eggs seems to be that of Hydrophilus aterrimus reported by Megušar ('o6). The eggs of this water beetle are laid in a boat-like cocoon which is kept in an upright position in the water by means of a peculiar mast. Megusar found that if these cocoons were inverted, thus also inverting the eggs within, the development of the eggs was retarded and a deformity in the embryos resulted. The small number of larvæ that hatched lived for only a short time.

$\checkmark$ A BRIEF ACCOUNT OF THE NORMAL EMBRYONIC DEVELOPMENT

OF CALLIGRAPHA BIGSBYANA

Eggs that have just been laid contain polar bodies in various phases of formation; these are given off into a thickening of the "Keimhautblastem" at a point slightly anterior to the median transverse axis of the egg. The female pronucleus lies in an amcoboid accumulation of cytoplasm among the yolk-globules. It moves inward and conjugates with the male pronucleus at a point level with the polar bodies. Here the first cleavage divisions take place. As cleavage progresses a separation of the nuclei into two sections occurs. The nuclei of one group form a more or less regular layer equidistant from the periphery; these preblastodermic nuclei (Fig. 17, pbl. n) move outward and fuse with the "Keimhautblastem." Cell walls now appear for the first time and a blastoderm is formed of a single layer of regularly arrarged cells. The nuclei of the other group (vitellophags), remain behind scattered throughout the yolk (Fig. I7, vt). Eight of the nuclei that reach the posterior end of the egg do not remain 


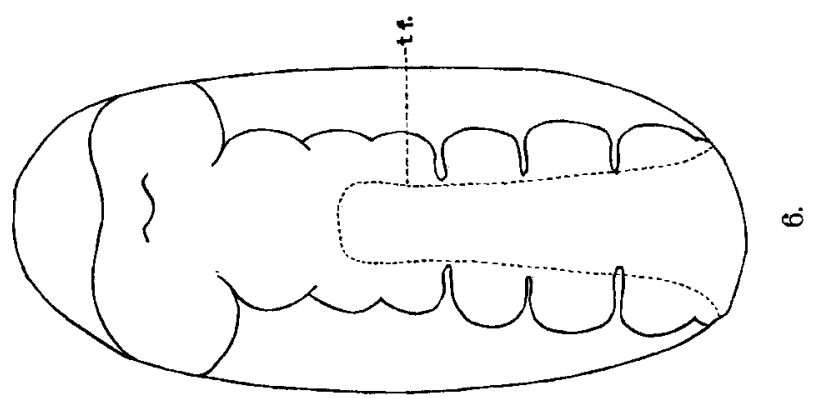

में

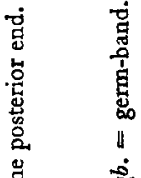

这

مأ

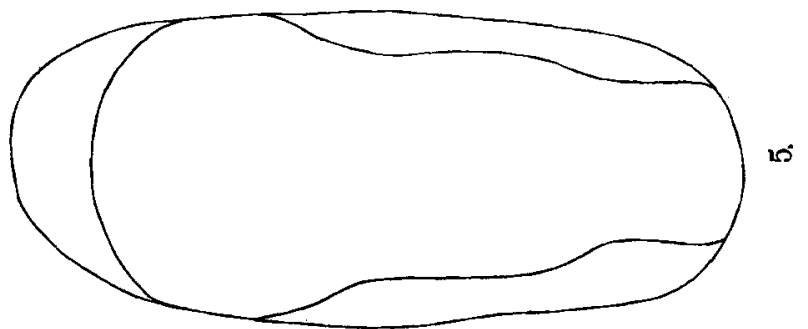

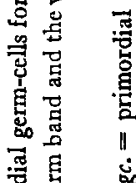

胥

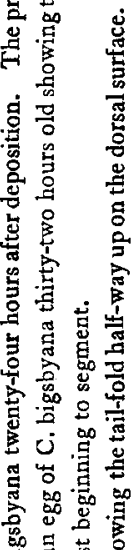

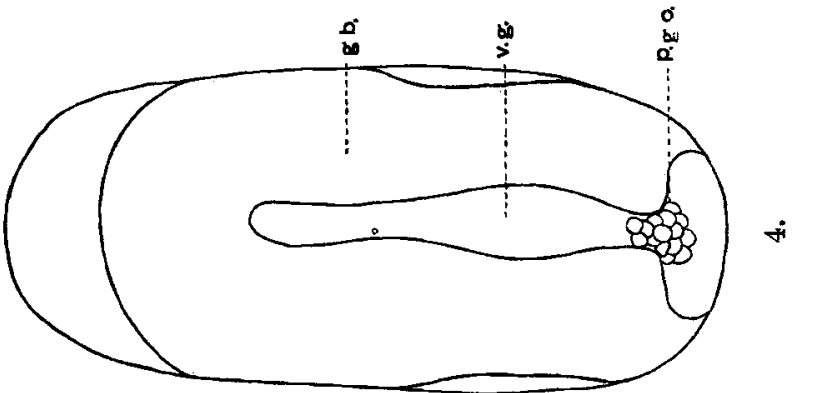

范营

ن 诺

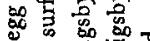

类

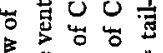

要造

岁要题

政

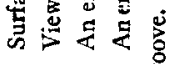

$m+n \infty$

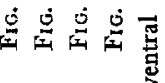


in the peripheral layer, but collect about them a number of granules (germ-cell determinants, Fig. $17, g c d$ ) which they encounter in this region and continue their migration until they are entirely separated from the blastoderm. These are the primordial germcells ( Fig. 3,p.gc). The first change noticed in the blastoderm is a crowding together of the cells on the ventral surface of the egg. This results in the formation of a broad longitudinal band of closely aggregated cells, the ventral plate. The edges of this plate are

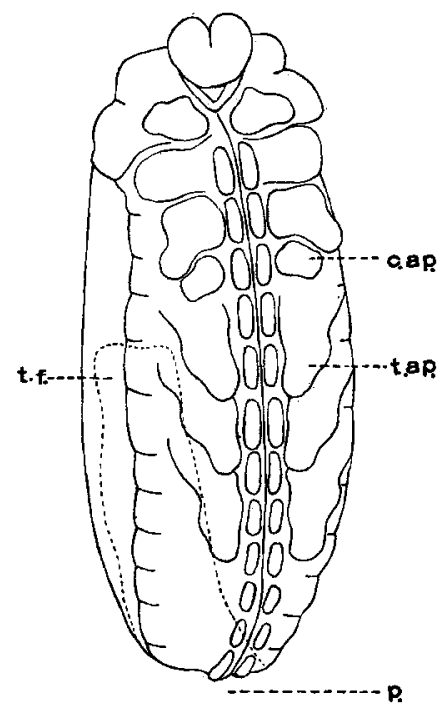

7.

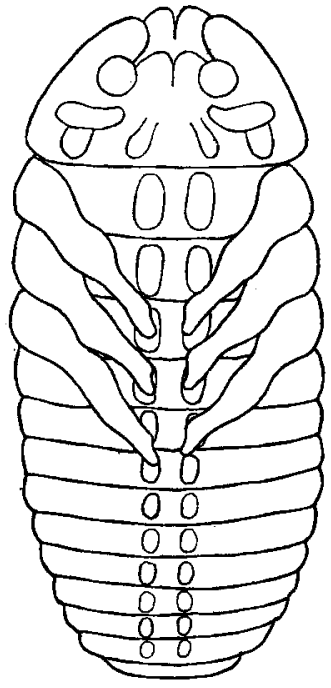

8.

FIG. 7 Surface view of embryo described in Series C.B. 2, c. The embryo has begun to broaden and shorten.

FIG. 8 An embryo of C. bigsbyana in which the tail-fold is coincident with the posterior end of the egg. $c . a p_{.}=$cephalic appendage. $p_{.}=$posterior. t.ap. $=$thoracic appendage. $t . f .=$ tail-fold.

thrown up into two folds; these spread out in the posterior region extending to the end of the egg where they pass around the primordial germ-cells and meet on the dorsal surface. The ventral plate now decreases both in length and in breadth and a longitudinal concavity, the ventral groove, appears. The germ-band can now be recognized; it covers the entire ventral surface of the egg except a wedge-shaped area anterior to the groove (Fig. $4, g b$ ). 
The germ-band becomes narrower as development advances; its posterior end pushes around that end of the egg and up on the dorsal surface. The lateral folds gradually cover over the ventral groove and the amnioserosal fold grows forward from the posterior

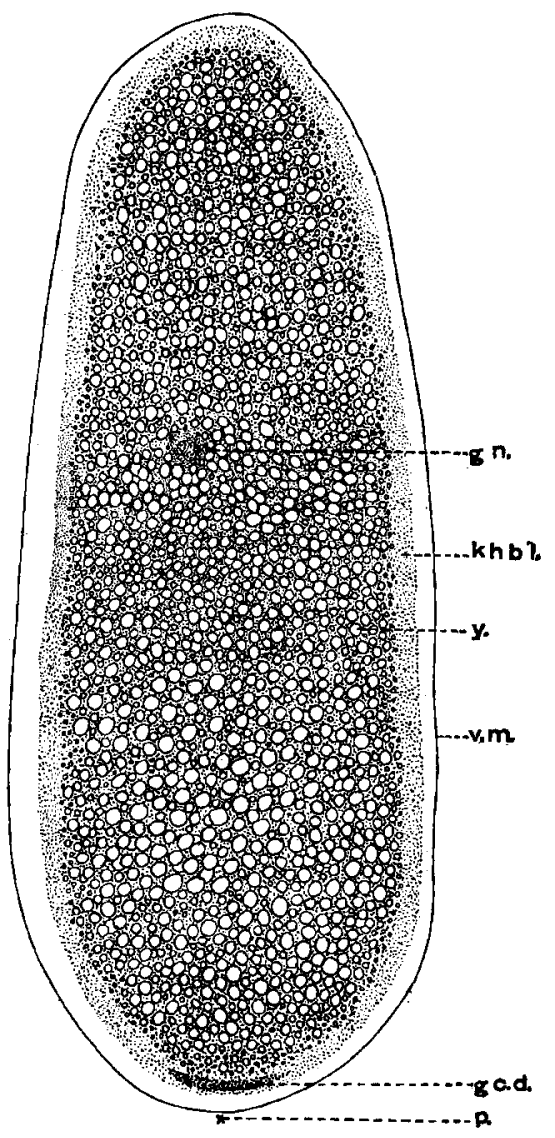

FIG. 9 Longitudinal section through an egg of C. bigsbyana four hours after deposition. gc.d. = germ-cell determinants. $g n,=$ germ-nuclei copulating. $k h b l .=$ "Keimhautblastem." $p_{.}=$posterior. v.m. $=$ vitelline membrane. $y_{.}=$yolk.

end to meet the anterior fold (Fig. 5). The segmentation of the germ-band and the lengthening of the entire embryo now progresses rapidly. The cephalic extremity extends almost to the 
anterior end of the egg and the tail-fold extends a little more than half-way up on the dorsal surface (Fig. 6). The tail-fold now begins to recede as the embryo shortens and broadens (Fig. 7) and in a short time coincides with the posterior end of the egg. The embryo now grows laterally around the yolk (Fig. 8), its various parts being situated approximately in the positions they occupy at the end of about six days when it hatches as a larva.

VI THE STRUCTURE OF THE EGG OF CALLIGRAPHA BIGSBYANA

AT THE TIME OF DEPOSITION

At the time of laying the eggs of Calligrapha bigsbyana are not always in the same stage of development, although usually polar body formation is taking place. The egg figured (Fig. 9) was fixed four hours after deposition. The polar bodies have already been produced in this egg and the male and female nuclei are in the act of conjugation. The egg consists of a large central mass of yolk and a comparatively thin peripheral layer of cytoplasm, the "Keimhautblastem" of Weismann. The interdeutoplasmic spaces are filled with cytoplasm which is connected with the "Keimhautblastem" by delicate strands of the same material. The enormous amount of yolk contained in the eggs of these insects makes the identification of other substances extremely difficult. The yolk-globules range in size from large deutoplasmic spheres to small granules, and, as the dissolution of some of them is continually taking place, one is unable to determine where yolk ends and cytoplasm begins. The only accumulations of cytoplasm large enough for examination are those surrounding the nuclei within the yolk mass, and the peripheral layer, the "Keimhautblastem." No differences in composition or staining qualities were observed between the cytoplasm of these two regions. The "Keimhautblastem" consists of a fluid ground substance in which are suspended very fine granules. It is a homogeneous layer of cytoplasm everywhere except at the posterior end of the egg. At this point there is a disc-shaped mass of larger granules imbedded within the inner portion of it. These granules stain deeply with hæmatoxylin. They are easily seen not only in sections but also 
in eggs that have been properly stained in toto. Because of their ultimate fate, as explained in the introduction, I have called these granules the germ-cell determinants (Fig. $9, g c . d$ ).

\section{THE EFFECTS OF CENTRIFUGAL FORCE UPON EGGS CENTRI- FUGED AFTER DEPOSITION}

Table I presents in concise form the main points in the series of experiments which have been selected for detailed description. Besides the thirteen series noted here there are also two tables (XI and XII) which give the results of a number of other series of experiments which were not considered of sufficient importance to describe at length.

TABLE I

List of the experiments described in detail

\begin{tabular}{|c|c|c|c|c|}
\hline Name & Number of series & $\begin{array}{c}\text { Age when centri- } \\
\text { fuged }\end{array}$ & $\begin{array}{l}\text { Length of time } \\
\text { centrifuged }\end{array}$ & Orientation \\
\hline C. bigsbyana & C.B.4. & ○ & $15 \mathrm{~min}$. to $4 \mathrm{hrs}$. & post. end in \\
\hline " & C.B. 3 & 0 & 4 hours & ant. end in \\
\hline * & C.B. 10 & $\circ$ & 6 hours & side in \\
\hline 4 & C.B. 9 & $\circ$ & 6 hours & post. end in \\
\hline “ & C.B. 2 & 14 hours & I hour & a \\
\hline : & C.B. 5 & 2 I hours & 2 hours & $"$ \\
\hline C. multipunctata & C.M. I & 0 & 16 hours & $"$ \\
\hline c. lunata & C.L. $a$ & I hour & 12 hours & $"$ \\
\hline “ & C.L. I & 9 hours & 12 hours & ant. end in \\
\hline L. decemlineata & L.D. I & 2 hours & $5 \mathrm{~min}$. to $2 \frac{1}{2} \mathrm{hrs}$ & post. end in \\
\hline$"$ & L.D. I & 0 & 5 days & a \\
\hline$"$ & L.D. 2 & o & 7 days & “ \\
\hline Lema trilineata & L.T. I & 0 & 2 hours & “ \\
\hline
\end{tabular}

Series C.B. 4 -Table II

The eggs of this series were centrifuged as soon as laid. They were held in place with their posterior ends towards the axis of rotation. Two eggs were removed at the intervals indicated in Table II; one of these two was fixed immediately, the other was allowed to develop. If the latter did not hatch within a period several days longer than the normal hatching time it was fixed. 
TABLE II

Calligrapha bigsbyana-Series C.B. 4

\begin{tabular}{|c|c|c|c|c|c|}
\hline $\begin{array}{c}\text { Number of } \\
\text { experiment }\end{array}$ & $\begin{array}{c}\text { Age when cen } \\
\text { trifuged }\end{array}$ & $\begin{array}{l}\text { Length of time } \\
\text { centrifuged }\end{array}$ & $\begin{array}{l}\text { Intervalbetween } \\
\text { end of experi- } \\
\text { ment and fixa- } \\
\text { tion }\end{array}$ & Orientation & Remarks \\
\hline C.B. $4, a$ & Control & & & & \\
\hline C.B. $4, b$ & 0 & 15 minutes & 0 & & \\
\hline C.B. $4, c$ & $\circ$ & 30 minutes & 0 & & \\
\hline C.B. $4, d$ & 0 & I hour & ० & & \\
\hline C.B. $4, e$ & $\circ$ & 2 hours & $\circ$ & Posterior end & \\
\hline C.B. $4 . f$ & o & 4 hours & o & toward axis of & \\
\hline C.B. $4, g$ & o & 15 minutes & 6 days & rotation & Normal larva \\
\hline C.B. $4, h$ & o & 30 minutes & 6 days & & Normal larva \\
\hline C.B. ${ }_{4, i}$ & a & I hour & Io days & & Did not hatch \\
\hline C.B. $4, j$ & 0 & 2 hours & ro days & & Did not hatch \\
\hline C.B. $4, k$ & ० & 4 hours & Io days & & Did not hatch \\
\hline
\end{tabular}

The progressive effect of a centrifugal force upon the distribution of the contents of the egg is shown by these experiments. They also furnish data concerning the amount of disturbance necessary to prevent the hatching of a normal larva.

C.B. 4, a. Sections of the fresh control egg of this series show a condition similar to that illustrated in Fig. 9 .

C.B. $4, b$. An egg centrifuged for fifteen minutes is very slightly affected. The "Keimhautblastem" has apparently not been changed at all. The yolk shows a partial redistribution; the larger, heavier globules have begun to move toward the outer end of the egg, i.e., the end away from the axis of rotation, and the inner portion of the yolk mass is almost entirely composed of the smaller globules. The pole-disc occupies its normal position at the posterior end of the egg; all about it are small, irregular vesicular spaces which are no doubt caused by the accumulation of the lighter fats in this region. No polar bodies could be discovered in the sections of this egg, but no significance can be attached to this fact as they cannot always be found in normal eggs.

$C . B$ 4, c. The effects of centrifugal force applied to this egg for thirty minutes are similar to those just recorded for C. B. $4, b$; the changes however are more pronounced. We find that there are 
more of the large yolk-globules near the outer end and less of them at the other pole. There is also a slight thickening of the "Keimhautblastem" at the sides of the egg near the inner end. The pole-disc is present in its usual position, but it is surrounded by a greater number and larger, irregular vesicles than in C. B. $4, b$.

C.B. 4, d. An egg taken from the centrifugal machine at the end of an hour is definitely stratified, two distinct layers being visible. There is a small cap of orange-colored material situated at the extreme inner end, while the rest of the egg representing the other layer has changed in color because of the redistribution of the yolk. The intense yellow color of the outer end is due to the invasion of a vast number of large deutoplasmic spheres into that region. No definite layers can be distinguished in this large portion, since the change in color from bright yellow at the outer end to pale yellow at the inner end is gradual. A longitudinal section through this egg is shown in Fig. ro. Most of the large yolkglobules lie in the outer region; the interdeutoplasmic spaces are entirely free from the cytoplasm which usually fills them. The "Keimhautblastem" has been forced almost entirely away from the outer end and from the periphery of the outer third of the egg and has added its mass to that of the inner region. At the extreme inner end one large, bud-like protrusion (one-third the short diameter of the egg) and several smaller ones have formed. They are covered externally by a thin layer of "Keimhautblastem" and are composed of a great number of vesicles. A similar vesicular portion was noted in the two eggs described above (C.B. $4, b$ and $c)$, but it has in this egg reached such proportions that we shall hereafter call it the vesicular zone. This is the material which appeared bright orange in color in the living centrifuged egg. Only one nucleus could be discovered in the entire egg. This is situated at one side near the inner end, as shown in Fig. Io, $n$. The pole-disc has moved from its position at the end and has traveled en masse away from the axis of rotation. It has carried that portion of the "Keimhautblastem" in which it is suspended along with it, producing a distinct depression at one side of the inner end of the egg. The sections containing the pole-disc fell outside 
of the vesicular zone so that a figure has been introduced to show the change in position of this structure (Fig. I I, $g c . d$ ).

C.B. 4, e. A third layer makes its appearance if a fresh egg is centrifuged for two hours. Before fixation this appears as a

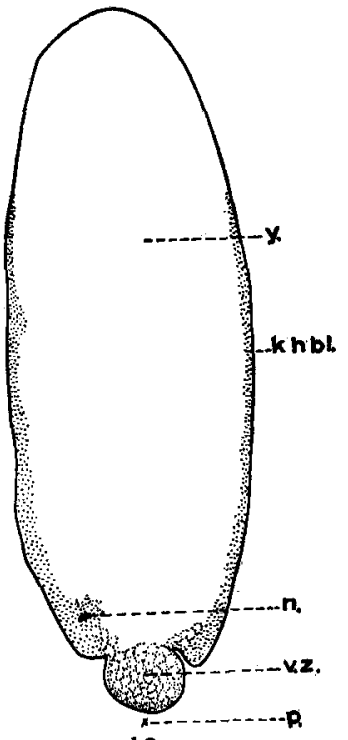

10.

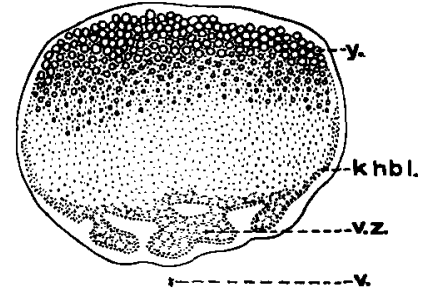

14.

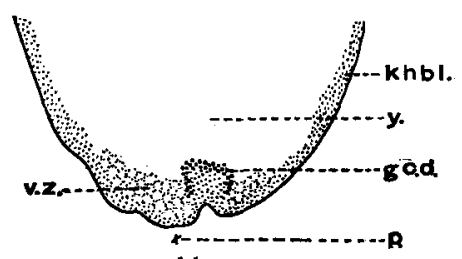

11.

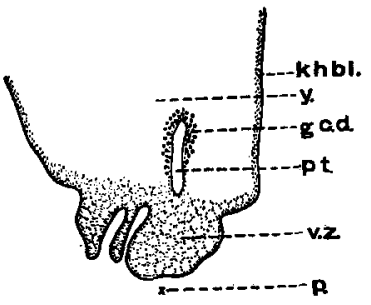

12.

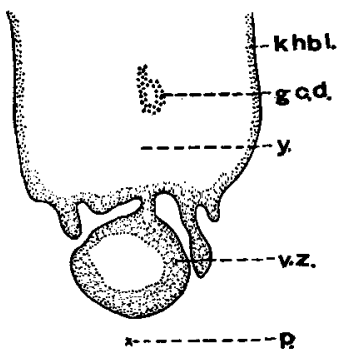

13.

Frg. to Longitudinal section through egg C.B. $4, d$.

Fig. II. Longitudinal section through the posterior end of egg C.D. 4, $d$, showing the effects of a centrifugal force applied for one hour upon the position of the pole-disc (ge.d.).

Fig. 12 Longitudinal section through the posterior end of egg C.B. 4 , $e$, showing the effects of a centrifugal force applied for two hours upon the position of the pole-disc.

Frg. 13 Longitudinal section through the posterior end of egg C.B. $4, f$, showing the effects of a centrifugal applied for four hours upon the position of the pole-disc. gc.d. = germ-cell determinants (pole-disc). $k h b l .=$ "Keimhautblastem." $n_{t}=$ nucleus. $p_{*}=$ posterior. $p_{*}=$ pathway made by the outward movement of the pole-disc. $v_{0}=$ ventral. $\quad$ o.x. $=$ vesicular zone. $y .=$ yolk.

Fig. I4 Transverse section through egg C.B. Io, $c$. 
colorless cap at the outer end. The sections show it to consist of a small mass of gray material which is heayier than the large yolk-globules. I shall call this the gray cap. It is composed of very small granules, does not stain like yolk nor as intensely as the cytoplasm of the "Keimhautblastem." The pole-disc has moved forward during the second hour the egg was centrifuged, and now lies anterior to its original position about one-fourth of the total length of the egg. In its progress it has pushed its way forcibly through the yolk mass, leaving a long, narrow, open pathway behind it (Fig. 12, pt). No nuclei were found in the sections.

C.B. 4, f. This egg was centrifuged for four hours and then fixed. A surface view of the egg stained in toto revealed a large central, colorless bud at the posterior (inner) end surrounded by a number (at least seven) of smaller buds. These are produced by wrinkles or folds in the surface of this region, due either to poor fixation or to a decrease in turgidity at the inner end. The entire egg seems to have been shortened slightly antero-posteriorly by the continued application of centrifugal force. The longitudinal sections made of this egg are not perfect, certain portions of the outer end being lost because of the accumulation of large yolk-globules (yolk which is not imbedded in cytoplasm is liable to break on the knife in cutting). I cannot be positive, therefore, of the presence of a gray cap in this egg. There is little doubt, however, that this structure was not absent in this instance, since the other eggs similarly treated possess a gray cap. The vesicular zone has increased in size during the last two hours this egg was centrifuged, and has been folded into larger bud-like prominences than were noted in the last egg described (C.B. 4,e). The pole-disc has made further progress in its journey away from the inner end. It has now reached a point about one-third of the total length of the egg anterior to its original position (Fig. $13, g c . d$ ). The open pathway which was observed behind it in C.B. $4, e$, has become closed and the "Keimhautblastem" that was pulled in with it has passed back and taken part in the vesicular layer.

C.B. 4, g. A normal larva hatched from an egg centrifuged for fifteen minutes with the posterior end towards the axis of rota- 
tion. The hatching period of approximately six days is the normal one for eggs of this species.

C.B. $4, h$. This egg, which was centrifuged for thirty minutes, also developed normally, the larva hatching in six days.

C.B. $4, i, j$ and $k$. None of these eggs continued its development farther than the early cleavage stages.

TABLE III

Calligrapha bigsbyana-Series C.B. 3

\begin{tabular}{|c|c|c|c|c|c|}
\hline $\begin{array}{l}\text { Number of } \\
\text { experiment }\end{array}$ & $\begin{array}{c}\text { Age when cen } \\
\text { trifuged }\end{array}$ & $\begin{array}{l}\text { Length of time } \\
\text { centrifuged }\end{array}$ & $\begin{array}{c}\text { Interval } \\
\text { between end of } \\
\text { experiment and } \\
\text { firation }\end{array}$ & Orientation & Remarks \\
\hline C.B. $3, a$ & Control & & & & \\
\hline C.B. $3, b$ & o & 4 hours & o & Anterior end & \\
\hline C.B. $3, c$ & o & 4 hours & 37 hours & toward axis of & Did not develop \\
\hline C.B. $3, d$ & o & 4 hours & 61 hours & rotation & “ \\
\hline C.B. $3, e$ & ○ & 4 hours & 96 hours & & “ \\
\hline C.B. $3, f$ & o & 4 hours & $6 \frac{1}{2}$ days & & " \\
\hline
\end{tabular}

Series C.B. 3-Table III

Series C.B. 3 will serve to show the effects of a centrifugal force applied for four hours to fresh eggs with their anterior ends toward the axis of rotation.

C.B. 3, a. The control egg was normal and in a stage slightly younger than that shown in Fig. 9.

C.B. 3, b. When taken from the centrifugal machine at the end of four hours this egg appeared stratified in a manner exactly like that of C.B. 4, e. Longitudinal sections show a gray cap at the heavy outer end, a middle zone of yolk and an inner light vesicular zone. The distribution of the "Keimhautblastem" is also similar to that in an egg centrifuged with the opposite (posterior) end toward the axis of rotation, i.e., it has moved toward the lighter end of the egg. The inner pole is creased and folded as in C.B. 4, e. One nucleus is present near the vesicular zone. The pole-disc remained at the posterior end of the egg near one side; 
it fell outside of those sections containing parts of the gray cap so that I was unable to determine whether it is of greater or less specific gravity than the later substance.

C.B. $3, c, d, e$, and $f$. These eggs did not develop very far, although the youngest $(3, c)$ contained a number of nuclei in the course of disintegration. Sections of the other eggs $(3, d, e$ and f) show a further dissolution of the nuclei, the vacuolation of the "Keimhautlbastem" and other evidences of catabolism.

TABLE IV

Calligrapha bigsbyana-Series C.B. to

\begin{tabular}{|c|c|c|c|c|c|}
\hline $\begin{array}{l}\text { Number of } \\
\text { experiment }\end{array}$ & $\begin{array}{c}\text { Age when cen } \\
\text { trifuged }\end{array}$ & $\begin{array}{c}\text { Length of time } \\
\text { centrifuged }\end{array}$ & $\begin{array}{c}\text { Interval } \\
\text { between end of } \\
\text { experiment and } \\
\text { fixation }\end{array}$ & Orientation & Remarks \\
\hline C.B. $10, a$ & Control & & & & \\
\hline C.B. $10, b$ & $\circ$ & 4 hours & $\circ$ & Right side in* & \\
\hline C.B. Io, $c$ & $\circ$ & 4 hours & $\circ$ & Ventral side in & \\
\hline C.B. Io, $d$ & $\circ$ & 4 hours & $3^{6}$ hours & Right side in & \\
\hline C.B. Io, $e$ & $\circ$ & 4 hours & $4^{8 \text { hours }}$ & Right side in & \\
\hline C.B. $10, f$ & $\circ$ & 4 hours & 60 hours & Ventral side in & \\
\hline C.B. $10, g$ & 0 & 4 hours & 9 days & Right side in & \\
\hline C.B. $10, h$ & 0 & 4 hours & 9 days & Ventral side in & \\
\hline
\end{tabular}

* This means that the right side of the egg was placed toward the axis of rotation.

\section{Series C.B. IO-Table IV}

These experiments were undertaken to detemine if the position of the embryo upon the egg can be changed by altering the distribution of the cytoplasm. Four of the eggs were oriented in the centrifugal machine so that their right sides were toward the axis of rotation, the other three with their ventral surfaces toward the center.

C.B. Io, a. The control egg was in an early cleavage stage.

C.B. $I 0, b$ and $c$. No differences could be discovered between an egg centrifuged with its right side turned inward and one with its ventral surface in the same direction, either before or after 
fixation. The sections also show a similar arrangement of materials. Fig. 14 represents a transverse section through C.B. Io, $c$. There is a light vesicular zone at the side which was turned toward the axis of rotation; this is folded into bud-like prominences just as we found to be the case in C.B. $4, e$, and others. The yolkglobules are distributed in the usual manner, the large ones being on the heavy side. The "Keimhautblastem" has moved away from the side of greater specific gravity and toward the lighter side. No gray cap could be found. It is probable that the material which produces this zone has all been thrown to the outer side, but the area is too great to allow of any perceptible accumulation.

C.B. Io, $e, f, g$ and $h$. No one of these eggs developed beyond an early cleavage stage. The nuclei then disintegrated and the amœboid masses of cytoplasm in which they lay became vacuolated as did also the "Keimhautblastem."

TABLE V

Calligrapha bigsbyana-Series C.B. 9

\begin{tabular}{|c|c|c|c|c|c|}
\hline $\begin{array}{l}\text { Number of } \\
\text { experiment }\end{array}$ & $\begin{array}{l}\text { Age when } \\
\text { trifuged }\end{array}$ & $\begin{array}{c}\text { cen-Length of time } \\
\text { centrif uged }\end{array}$ & $\begin{array}{c}\text { Interval } \\
\text { between end of } \\
\text { experiment and } \\
\text { firation }\end{array}$ & Orientation & Remarks \\
\hline $\begin{array}{l}\text { C.B. } 9, a \\
\text { C.B. } 9, b \\
\text { C.B. } 9, e \\
\text { C.B. } 9, d \\
\text { C.B. } 9, e \\
\text { C.B. } 9, f\end{array}$ & $\begin{array}{c}\text { Control } \\
0 \\
0 \\
0 \\
0 \\
0\end{array}$ & $\begin{array}{l}6 \text { hours } \\
6 \text { hours } \\
6 \text { hours } \\
6 \text { hours } \\
6 \text { hours }\end{array}$ & $\begin{array}{c}0 \\
41 \text { hours } \\
65 \text { hours } \\
89 \text { hours } \\
10 \text { days }\end{array}$ & $\begin{array}{l}\text { Posterior end } \\
\text { toward axis of } \\
\text { rotation }\end{array}$ & \\
\hline
\end{tabular}

Series C.B. 9-Table V

Although these eggs were taken as soon as laid, sections through C.B. 9, $a$ show that they were in a rather advanced cleavage stage when the experiments were begun. They represent a condition intermediate between those of series C.B. 2 (Fig. I 7 ) and C.B. 4 (Fig. 9), resembling in structure an egg ten hours old. 
C.B. 9, b. Three zones are recognizable in this egg corresponding to those already described in egg C.B. $4, e$ and, although centrifuged for sixhours, no noticeable difference is discernible in the distribution of material in this egg and one of nearly the same age which was centrifuged for only one hour (C.B. 2, b). The nuclei of many of the vitellophags are distorted or disintegrating. The granules of the pole-disc have, as in normal eggs, become imbedded in the cytoplasm of the primordial germ cells; the latter occupy their usual position at this stage between the vitelline membrane and the blastoderm at the posterior pole.

C.B. 9, c. Two eggs were fixed forty-one hours after they were taken from the centrifugal machine. One of these did not develop, its nuclei disintegrating and the "Keimhautblastem" becoming vacuolated; the other carried an embryo with a distinct ventral groove (Fig. 15). Superficially this embryo resembles that of a normally developed egg of this age except that it does not reach as far anteriorly on the ventral surface, but extends farther around the posterior end and up on the dorsal surface (compare Figs. 4 and I5). It is evident that under the influence of centrifugal force the nuclei and "Keimhautblastem" have become massed in the posterior half of the egg, where development has continued. This egg if it had been allowed to develop would no doubt have produced an embryo resembling that described under C.M. I, $b$ (Fig. 2I). Sections of this egg show a rearrangement of the yolkglobules, a condition being reached similar to that illustrated in Fig. 9. The gray cap and vesicular zone are still present.

$C . B, d$. One of two eggs preserved sixty-five hours after being taken from the centrifugal machine did not develop; the other produced a shapeless mass of tissue, no definite organs being distinguishable. Fig. $\mathrm{r} 6$ is a diagram of a sagittal section through this egg. The gray cap and vesicular zone are still present, the former at one side of the outer end of the egg, the latter just dorsal to the embryonic tissue. 


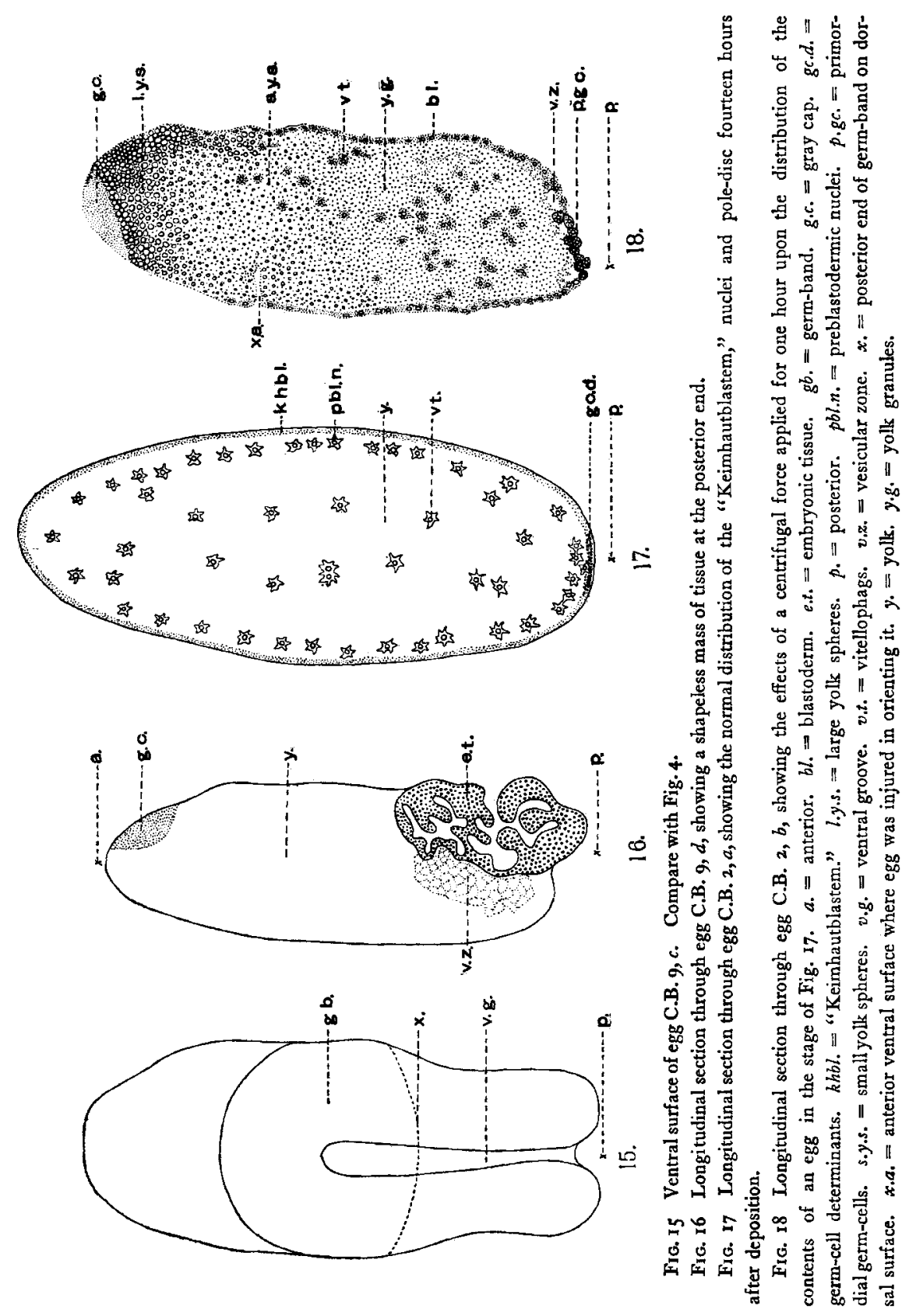


TABLE VI

Calligrapha bigsbyana-Series C.B. 2

\begin{tabular}{|c|c|c|c|c|c|}
\hline $\begin{array}{c}\text { Number of } \\
\text { experiment }\end{array}$ & $\begin{array}{c}\text { Age when cen- } \\
\text { trifuged }\end{array}$ & $\begin{array}{c}\text { Length of time } \\
\text { centrifuged }\end{array}$ & $\begin{array}{c}\text { Interval } \\
\text { between end of } \\
\text { experiment and } \\
\text { fixation }\end{array}$ & Orientation & Remarks \\
\hline $\begin{array}{l}\text { C.B. 2, } a \\
\text { C.B. 2,b } \\
\text { C.B. 2, C } \\
\text { C.B. 2, } d\end{array}$ & $\begin{array}{l}\text { control } \\
14 \text { hours } \\
14 \text { hours } \\
\text { 14 hours }\end{array}$ & $\begin{array}{l}\text { I hour } \\
\text { I hour } \\
\text { I hour }\end{array}$ & $\begin{array}{c}\circ \\
48 \text { hours } \\
6 \text { days }\end{array}$ & $\begin{array}{l}\text { Posterior end } \\
\text { toward axis of } \\
\text { rotation }\end{array}$ & $\begin{array}{l}\text { normal embryo } \\
\text { normal larva }\end{array}$ \\
\hline
\end{tabular}

Series C.B. 2-Table VI

The eggs used in these experiments were laid at 7 p.m. on July 19. One egg was fixed at the end of fourteen hours; the others were at the same time placed in the centrifugal machine with their posterior ends toward the axis of rotation and subjected to the usual number of revolutions for one hour.

C.B. 2, a. Fig. I7 shows the "Keimhautblastem," the poledisc and the distribution of the nuclei in the control egg, aged fourteen hours. The yolk is not included in this figure, as its distribution is similar to that of the freshly laid egg (Fig. 9). The two groups of nuclei, those which form a more or less regular layer near the periphery and will fuse with the "Keimhautblastem" in a few hours producing the blastoderm ( $p b l . n)$, and the vitellophags $(v t)$ scattered about in the yolk, are quite clearly marked at this stage. When taken from the centrifugal machine a colorless layer of material was observed at the outer end of the egg; this is the gray cap occupying a position similar to that noted under C.B. 4 , e. The color of the egg was deep yellow posterior to the gray cap and gradually faded out toward the inner end until near that pole it was almost colorless. A bright-yellow cap, the vesicular layer, occupied the extreme inner end. A sagittal section of this egg is shown in Fig. I8. At the anterior end is the heaviest substance in the egg, the gray cap. Just posterior to this we find the largest deutoplasmic spheres which gave to the living egg its bright-yellow color. The spaces among these are 
free from cytoplasm. The yolk-globules become smaller and smaller posteriorly until they cease altogether in the middle region, where smaller and lighter yolk granules take their place. At the posterior end there are many irregular vacuoles caused by the accumulation of fat in this region. During the hour the egg was under the influence of centrifugal force the preblastodermic nuclei (Fig. I $7 p b l$. $n$ ) migrated outward until they fused with the "Keimhautblastem" forming the blastoderm. The "Keimhautblastem" in the mean time flowed away from the anterior end of the egg, adding this portion to that posterior to it and producing a blastoderm in the latter region decidedly thicker than usual. The nuclei in the blastoderm seem to have been influenced by the centrifugal force; those near the central region have apparently been drawn out of their normal spherical shape and are now oval. As the inner pole is approached the nuclei become less and less oval until at the extreme end they are spherical as normally. The vitellophags have migrated toward the axis of rotation and the outer end is free from them altogether, while a greater number than usual are present near the posterior end. The centrifugal force used has apparently had no effect upon the position of the nuclei of the vitellophags in relation to the mass of cytoplasm which surrounds them, as in every case the nucleus is in or near the center. The direction of division of these vitellophags, however, seems to have been influenced for we find in almost every instance that the daughter cells produced by a recent division lie one posterior to the other, i.e., in the direction of the centrifugal force. The germ-cell determinants have found their way as usual into the primordial germ-cells at the extreme posterior end of the egg (Fig. I8, p.gc).

C.B. 2, c. A normal embryo (Fig. 7) was produced by this egg, which was fixed forty-eight hours after being centrifuged. Not the slightest difference could be discovered between an in toto preparation of this egg and a normally developed egg of the same age ( 63 hours). Sagittal sections show that the yolk has undergone segmentation and that the yolk-spheres and yolk-granules are equally distributed throughout the entire yolk mass. The germcells have migrated from the posterior amniotic cavity through the 
pole-cell canal and into the embryo and lie near the end of the tailfold. The gray cap has not entirely disappeared, but what I take to be a remnant of it is situated at the dorsal anterior surface.

C.B. $2, d$. A normal larva hatched from this egg in the average length of time required for eggs of this beetle when developed under natural conditions.

TABLE VII

Calligrapha bigsbyana -Series C.B. 5

\begin{tabular}{l|c|c|c|c|c}
\hline $\begin{array}{c}\text { Number of } \\
\text { experiment }\end{array}$ & $\begin{array}{c}\text { Age when cen } \\
\text { trifuged }\end{array}$ & $\begin{array}{c}\text { Length of time } \\
\text { centrifuged }\end{array}$ & $\begin{array}{c}\text { Interval } \\
\text { between end of } \\
\text { experiment and } \\
\text { fixation }\end{array}$ & Orientation & Remarks \\
\hline C.B. $5, a$ & control & & & Posterior end & \\
C.B. $5, b$ & 21 hours & 2 hours & 0 & $\begin{array}{c}\text { toward axis of } \\
\text { rotation }\end{array}$ & normal embryo \\
C.B. $5, c$ & 21 hours & 2 hours & 27 hours \\
C.B. $5, d$ & 21 hours & 2 hours & 6 days & & normal larva \\
\hline
\end{tabular}

\section{Series C.B. 5-Table VII}

This series of experiments was performed in order to discover if centrifugal force would have any appreciable effect on an egg in which the blastoderm has already been formed, and if so whether or not the egg would at this late stage continue to develop and eventually produce a larva.

C.B. 5 , a. The eggs of C. bigsbyana at the age of twenty-one hours have usually reached a stage in which a blastoderm of a single layer of cells completely covers the central yolk mass. Scattered about irregularly among the yolk-globules are numerous vitellophags. At the posterior pole are a number of cells lying in a closely packed group between the vitelline membrane and the egg (Fig. 3, pgc.); these are the primordial germ-cells (pole-cells) which a few hours earlier migrated through that part of the posterior end occupied by the pole-disc, taking the granules of which this is composed along with them.

C.B. $5, b$. The application of centrifugal force for two hours has very little effect upon an egg twenty-one hours old as seen in 
surface view. The surface at the inner end is creased and folded just as was found to be the case with younger eggs (C.B. $4, e$ ). Longitudinal sections through this egg present a distribution of material similar to that with which we are already familiar. A gray cap is present at the outer end (Fig. 19, g.c); the largest deutoplasmic spheres are adjacent to the gray cap, and there is a gradual decrease in the size of the yolk-globules until near the inner end where these are lacking altogether giving way to the vesicular zone. Most of the vittellophags have passed into the

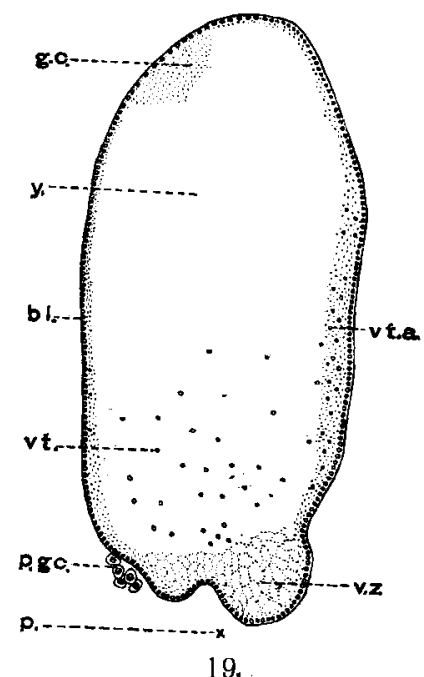

FIG. I9 Longitudinal section through egg C.B. 5, b., showing the effects of a centrifugal force applied for two hours upon an egg covered by a blastoderm. Explanation of letters same as Figs. 15-18. vt.a, $=$ vitellophags which have fused with the blastoderm.

inner half of the egg; a number of them seem to have fused with the "Keimhautblastem" in the equatorial region. As was the case with the "Keimhautblastem" in the younger eggs (C.B. 4,e) the superficial layer (blastoderm) has become thinner at the outer heavy end until it is barely visible at certain points; its mass has been added to that toward the inner end. The primordial germcells occupy their normal position at the posterior end of the egg.

C.B. 5, c. An egg in the condition just described was allowed 
to develop for twenty-seven hours and then preserved. Externally the embryo it carried appeared to be normal in every respect.

It was in a slightly younger stage than that of C.B. 2, c, shown in Fig. 7. Upon sectioning it was found that the vesicular zone had disappeared entirely, that the yolk had segmented and both this and the vitellophags had regained their normal distribution, but that there still remained a small amount of the heavy gray cap. The embryonic tissue seems to have sustained no ill effects from the centrifugal force.

C.B. $5, d$. A normal larva hatched from the remaining egg of this series in the average period, six days.

\section{Series C.M. I.}

Two freshly laid eggs of Calligrapha multipunctata placed with their posterior ends inward were centrifuged for sixteen hours at a rate much slower than that applied to the eggs in most of the other experiments. At the end of this period three perfectly distinct zones could be recognized by their colors. The nearly uniform pale-orange color of the normal egg had given way at the inner end to bright orange; at the opposite pole was a whitish cap, while the comparatively large central zone faded gradually from bright yellow at its outer end to pale yellow where it joined the inner orange stratum.

C.M. I, a. An in toto preparation of one of these eggs which was fixed immediately after being taken from the centrifugal machine shows that the three zones do not differ in color only, but are composed of three different substances. Sections of this egg show a stratification similar to that already described for C. bigsbyana (C.B. $4, e$ ). The stage of development, however, is unlike that of any egg so far examined. Fig. 20 shows the nuclei aggregated in the inner portion of the egg. The "Keimhautblastem" at the sides of the egg and surrounding the folded vesicular zone contains many nuclei producing a kind of blastoderm. The vitellophags have accumulated in the inner portion of the central zone. Many of these are either dividing by amitosis or seem to have recently completed such a division. 


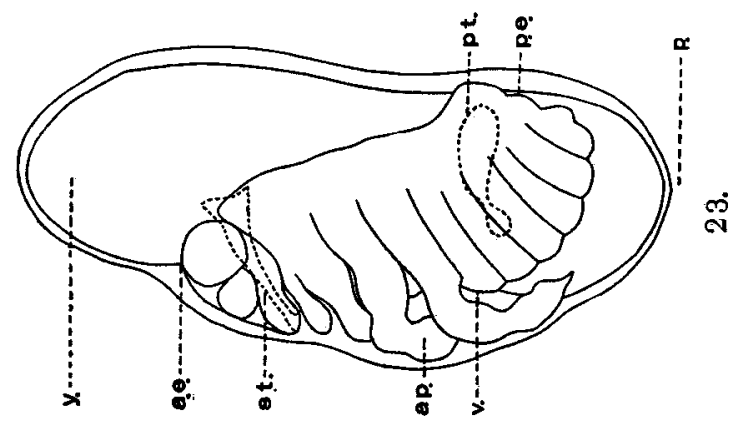

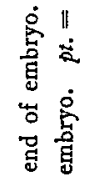

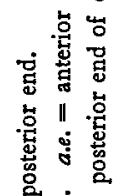

혐형

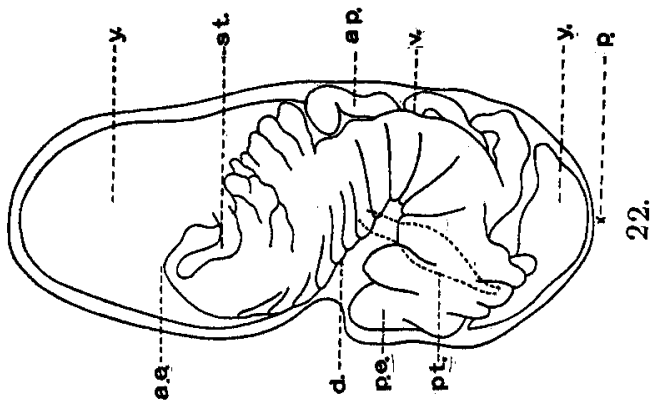

动

늉 녕

莒兽总

焉

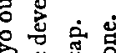

웜 过

表焉

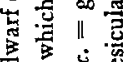

क क क

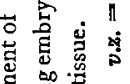

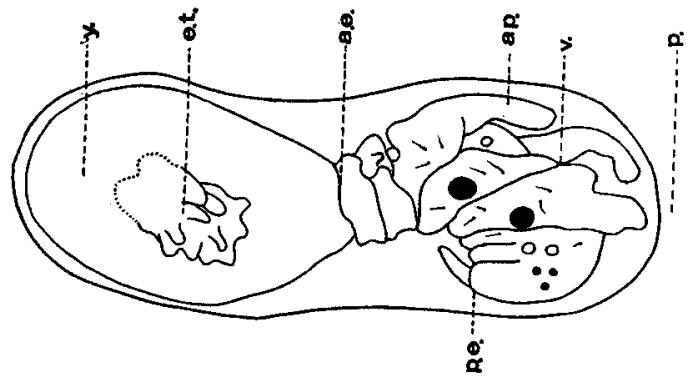

焉.

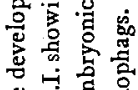

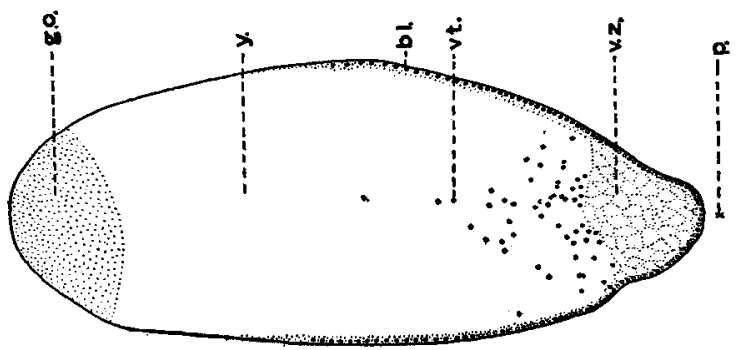

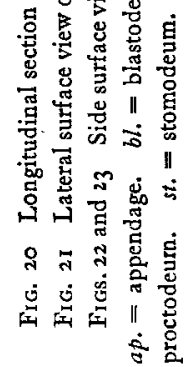


$C . M . I, b$. Fig. 2 I represents a surface view of the right side of an egg like that just described which was allowed to develop for nine days. The embryo has continued to develop at the inner (posterior) end. Its orientation is normal except that the entire embryo has shifted its position posteriorly so that the posterior end instead of being coincident with the posterior end of the egg is now part way up on the dorsal surface. A small mass of embryonic tissue is imbedded in the large mass of yolk. Normally this yolk would be surrounded by the embryo and become included within the mid-intestine; in this case a dwarf embryo has developed without growing around the nutritive material.

TABLE VIII

Calligrapha lunata-Series C.L., a

\begin{tabular}{|c|c|c|c|c|c|}
\hline $\begin{array}{r}\text { Number of } \\
\text { experiment }\end{array}$ & $\begin{array}{l}\text { Age when cen- } \\
\text { trifuged }\end{array}$ & $\begin{array}{c}\text { Length of time } \\
\text { centrifuged }\end{array}$ & $\begin{array}{c}\text { Interval } \\
\text { between end of } \\
\text { experiment and } \\
\text { fixation }\end{array}$ & Orientation & Remarks \\
\hline $\begin{array}{l}\text { C.I. } a, 1 \\
\text { C.L. } a, 2 \\
\text { C.L. } a, 3 \\
\text { C.L. } a .4\end{array}$ & $\begin{array}{c}\text { I hour } \\
" \\
" \\
"\end{array}$ & $\begin{array}{c}12 \text { hours } \\
" \\
“ \\
\text { “ }\end{array}$ & $\begin{array}{c}\circ \\
55 \text { hours } \\
79 \text { hours } \\
\left\{\begin{array}{l}24 \text { days } \\
18 \text { day larva }\end{array}\right.\end{array}$ & $\begin{array}{c}\text { Posterior end } \\
\text { toward axis of } \\
\text { rotation }\end{array}$ & hatched in 6 days \\
\hline
\end{tabular}

Series C.L. $a-$ Table VIII

The effects of centrifugal force upon the eggs of $C$. lunata are shown by this series of experiments. The results, as may be seen from a comparision of the above table and the following descriptions, differ only in minor details from those recorded for eggs of C. bigsbyana similarly treated.

C.L. $a, I$. This egg was stratified by the centrifugal force into three layers, a gray cap at the outer heavy end, a middle yolk zone with large deutoplasmic spheres at the outer end gradually decreasing in size toward the inner pole and a light vesicular layer at the extreme inner end. Longitudinal sections resemble those of C. M. I shown in Fig. 20. There are a number of nuclei present scattered about among the yolk-granules near the inner end of the middle zone. Each nucleus is approximately in the 
center of the amceboid mass of cytoplasm in which it lies embedded; the whole apparently has moved en masse toward the lighter end of the egg. The pole-disc is situated between the vesicular layer and the middle zone; it is probable that its change of position is due, not to any movement of the granules, but to the accumulation of lighter fats posterior to it.

C.L. a, 2. The only redistribution of material that has taken place since this egg was taken from the centrifugal machine is a movement of the "Keimhautblastem," resulting in several large accumulations at the periphery in the middle region. The nuclei have disintegrated and the "Keimhautblastem" has the vacuolated appearance indicative of its early dissolution. No larva could possibly have developed from this egg.

C.L. $a$, 3. Sections of this egg show a continuation of the catabolic processes mentioned in C. L. $a, 2$.

C.L. $a$, 4. The only egg which was not fixed before the end of the hatching period seems to have developed normally, as it produced a normal larva. I can account for this only on the assumption that the eggs of this series were differently affected by the centrifugal force and that C.L. $a, 2$ and C.L. $a, 3$ were too severely injured to continue their development while C.L. $a, 4$ was able to readjust itself to the new conditions imposed by the change in the position of the egg contents. A perfect series of sagittal sections was made through this larva; they showed no irregularicies in the size, position or structure of the internal organs. The reproductive organs (female) are in their proper positions.

TABLE IX

Calligrapha lunata-Series C.L.I.

\begin{tabular}{|c|c|c|c|c|c|}
\hline $\begin{array}{l}\text { Number of } \\
\text { experiment }\end{array}$ & $\begin{array}{l}\text { Age when cen- } \\
\text { trifuged }\end{array}$ & $\begin{array}{l}\text { Length of time } \\
\text { centrifuged }\end{array}$ & $\begin{array}{l}\text { Interval } \\
\text { between end of } \\
\text { experiment } \\
\text { and fixation }\end{array}$ & Orientation & Remarks \\
\hline $\begin{array}{l}\text { C.L.I. } a \\
\text { C.L.I. } b . \\
\text { C.L.I, } c \\
\text { C.L.I, } d \\
\text { C.L.I, } e\end{array}$ & $\begin{array}{c}\text { control } \\
9 \text { hours } \\
" \\
“ \\
"\end{array}$ & $\begin{array}{c}\text { I2 hours } \\
\text { " } \\
" \\
"\end{array}$ & $\begin{array}{c}\circ \\
24 \text { hours } \\
48 \text { hours } \\
4 \text { days }\end{array}$ & $\begin{array}{l}\text { Anterior end } \\
\text { toward axis of } \\
\text { rotation }\end{array}$ & hatched \\
\hline
\end{tabular}


Series C.L. I-Table IX

The effects of centrifugal force upon the eggs of $\mathrm{C}$. lunata when oriented with their anterior ends toward the center are shown by these experiments.

C.L., a. The control egg of this series proved to be in a stage similar to that already described for C. B. $9, a$.

C.L. $I, b$. After being centrifuged for twelve hours this egg showed the customary three strata. Longitudinal sections resemble those of C. M. I (Fig. 20); they differ from them only in the absence of a well-defined blastoderm in the inner region.

C.L. I, c. During the twenty-four hours since this egg was taken from the centrifugal machine the yolk has had time to redistribute itself to some extent and many of the larger globules are present at the lighter end. Development has proceeded and the inner half of the egg is one large syncytium in the center of which is the vesicular zone containing a few nuclei.

C.L. $I, d$. Sections of this egg may be compared with that of C.B. 9, $d$, shown in Fig. I6. There is a mass of tissue at the inner end which is thrown up into folds, but no definite structures are distinguishable in it.

C.L. I, e. The only egg that was allowed to develop throughout the entire hatching period produced a larva at the end of six days. This larva is apparently normal. It was preserved when three days old.

TABLE $\mathbf{X}$

Leptinotarsa decemlineata-Series L. D. $l$

\begin{tabular}{|c|c|c|c|c|c|}
\hline $\begin{array}{l}\text { Number of } \\
\text { experiment }\end{array}$ & $\begin{array}{c}\text { Age when cen- } \\
\text { trifuged }\end{array}$ & $\begin{array}{l}\text { Length of time } \\
\text { centrifuged }\end{array}$ & \begin{tabular}{|} 
Interval \\
between end of \\
experiment \\
and fixation
\end{tabular} & Orientation & Remarks \\
\hline $\begin{array}{l}\text { L.D. 1, I } \\
\text { L.D. 1, } 2 \\
\text { L.D. 1, } 3 \\
\text { L.D. 1, } 4 \\
\text { L.D. 1, } 5 \\
\text { L.D. 1, } 6 \\
\text { L.D. 1, } 7\end{array}$ & $\begin{array}{c}\text { control } \\
2 \text { hours } \\
\text { " } \\
\text { " } \\
\star \\
\text { " } \\
\text { " }\end{array}$ & $\begin{array}{l}5 \text { minutes } \\
10 \text { minutes } \\
20 \text { minutes } \\
45 \text { minutes } \\
1 \frac{1}{2} \text { hours } \\
2 \frac{1}{2} \text { hours }\end{array}$ & & $\begin{array}{l}\text { Posterior end } \\
\text { toward axis of } \\
\text { rotation }\end{array}$ & $\begin{array}{c}\text { hatched in } 6 \text { days } \\
" \\
" \\
" \\
" \\
"\end{array}$ \\
\hline
\end{tabular}


The above table (Table $\mathrm{X}$ ) shows the results of a graded series of experiments upon eggs of Leptinotarsa decemlineata centrifuged from five minutes to two hours and one half. These eggs, including the control (L. D. $l, \mathrm{I}$ ) all hatched at the same time, showing that the amount of centrifugal force has no perceptible influence upon the rate of development.

\section{Series L.D. I}

L.D. I. A number of fresh eggs of the potato beetle, Leptinotarsa decemlineata, were centrifuged at a low rate of speed $(360$ revolutions per minute) for five days. They were oriented with their posterior ends toward the axis of rotation. The resulting embryos (Figs. 22 and 23), which of course would not have hatched, are very similar in appearance to that described under C. M. I, $b$. The heavy substances in these eggs are apparently non-essential for the development of the embryo, being made up principally of nutritive yolk. When deprived of this material a dwarf embryo is produced at the inner end of the egg.

\section{Series L.D. 2}

Another batch of potato beetles' eggs were centrifuged at the same rate of speed for seven days. Dwarf embryos developed at the inner light end in every case. No sections were made of these embryos.

\section{Series L. T. I}

A number of eggs of Lema trilineata were centrifuged with their posterior ends turned inward. In all cases the stratification induced resembles that of the eggs of C. bigsbyana similarly treated.

Table XI presents the data obtained from a number of experiments which have been selected from fifteen series of the eggs of Calligrapha lunata. Eight of these centrifuged eggs produced larvæ in the normal hatching period; of these, four were centrifuged with their posterior poles toward the axis of rotation, three with their anterior ends toward the center and one with its side turned 
TABLE XI

Calligrapha lunata

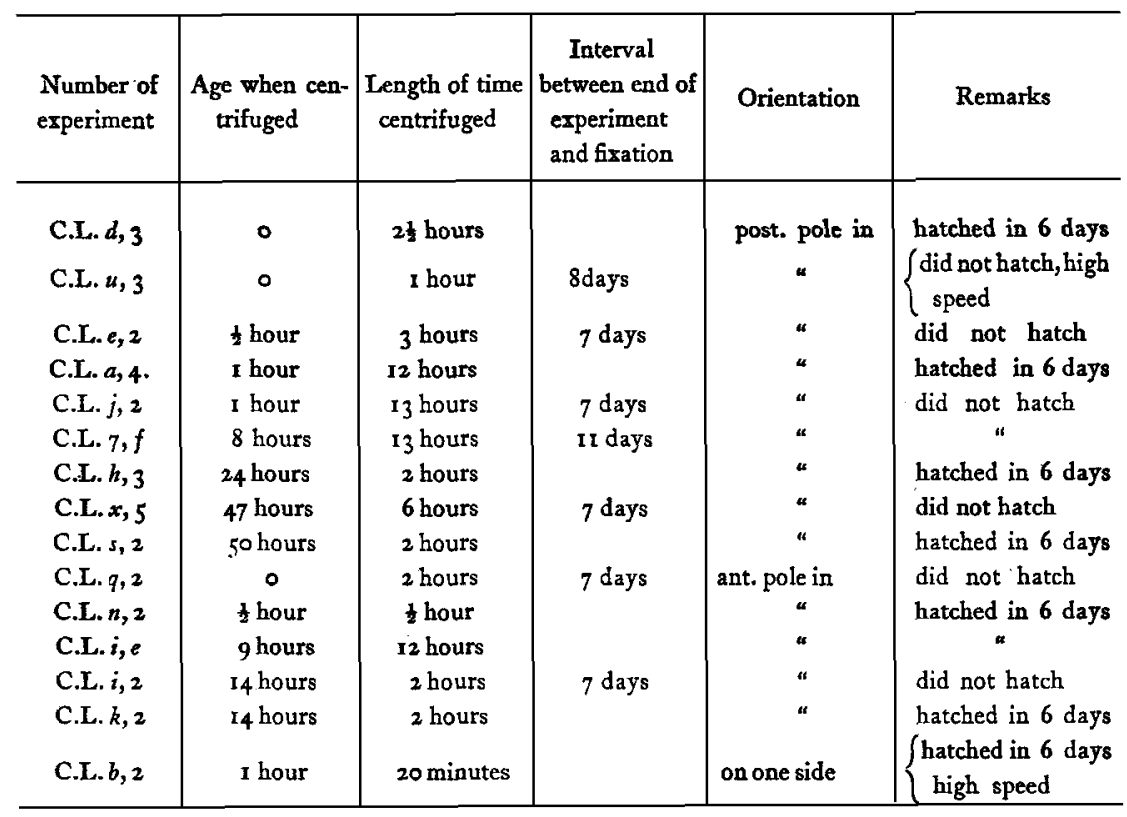

TABLE XII

Leptinotarsa decemlineata

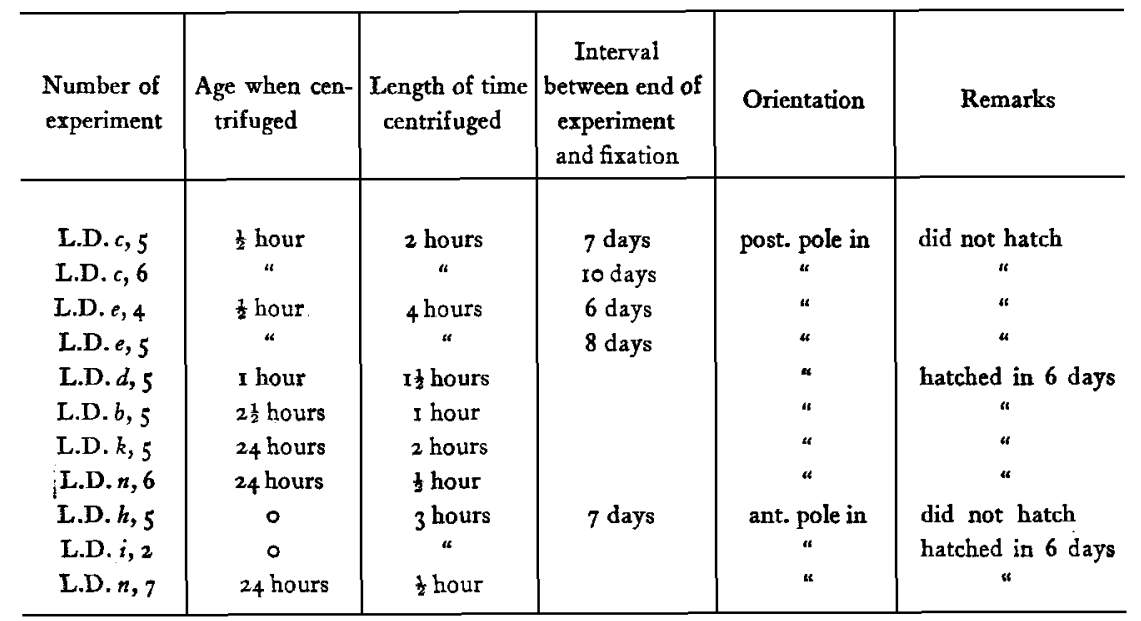


inward. The age when the eggs were centrifuged ranges from freshly laid to fifty hours. The length of time centrifuged ranges from twenty minutes to twelve hours. It is obvious that there is no definite total amount of centrifugal force which will prevent the hatching of the egg. The orientation of the egg is apparently of no importance.

The data given in Table XII have been selected from eleven series of experiments upon the eggs of Leptinotarsa decemlineata. There are too few items in this list to warrant any general conclusions, but the experiments tend to show that an older egg has greater chances of producing a larva after being centrifuged than does one experimented upon a short time after deposition. Both eggs oriented with the posterior end toward the axis of rotation and those with the anterior end toward the center gave rise to normal larvæ.

VIII THE EFFECTS OF CENTRIFUGAL FORCE UPON EGGS LAID BY CENTRIFUGED BEETLES.

\section{$I$ Experiments with C. bigsbyana}

Series C.B. 12

A female C. bigsbyana was centrifuged at the usual rate of speed for two hours and fifteen minutes with her posterior end toward the axis of rotation. When taken from the machine she seemed to suffer no ill effects but proceeded to walk about and feed as usual. Three days later, July 24, five eggs were laid; two of these were fixed at once and the other three allowed to develop. The former showed no outward signs of any disturbances due to centrifugal force. Sections also failed to disclose any rearrangement of materials. The eggs that were left to develop were fixed at the end of eight days. A superficial view of one of these is shown in Fig. 24; a shapeless mass of tissuelies imbedded within the disintegrated yolk mass.

$$
\text { Series C.B. I3 }
$$

The same beetle as that of Series C. B. I2 laid a second batch of five eggs two hours after the first five were deposited. Two of 
these which were fixed immediately showed no effect of centrifugal force; the other three hatched in six days.

\section{Experiments with Leptinotarsa decemlineata}

\section{Series L.D. $f$}

At 3:30 p.m. on July $I_{7}$ a female L. decemlineata was centrifuged for one hour with her posterior end toward the center.

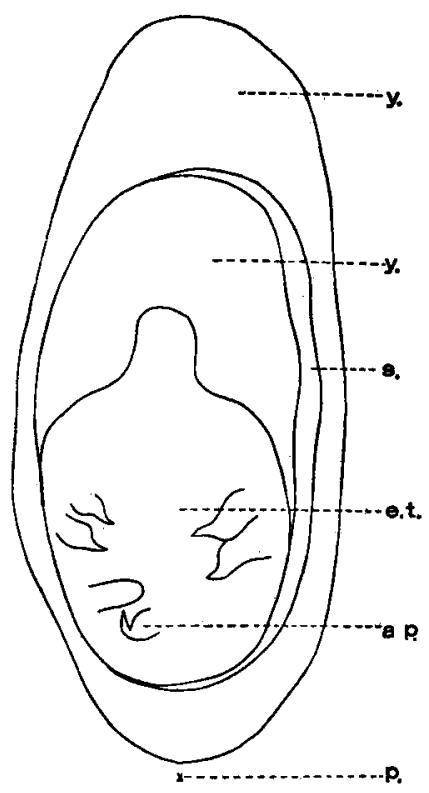

24.

Fig. 24 Surface view of egg C.B. 12 laid by a centrifuged beetle. $a p .=$ appendage. $e_{. t} .=\mathrm{cm}$ bryonic tissue. $p_{.}=$posterior. $s_{.}=$space between two yolk masses. $y_{.}=$yolk.

One egg was laid an hour after being centrifuged and others were laid at irregular intervals until 9:30 the next morning, when the total number reached seventy. The first egg laid, as well as all of the others in the series, showed a stratification produced by centrifugal force. Only two layers, however, resulted, nogray cap being discovered in the sections. The vesicular zone is not as large as in older eggs centrifuged outside of the body of the mother for a 
similar length of time, but the yolk-globules have a distribution almost exactly like that induced in the latter. Many of the eggs were allowed to develop; all of these hatched in six days.

\section{Series L.D. $m$}

The same beetle as that of Series L.D. $f$ laid a batch of eggs at 7 p.m. July 19 , i.e., fifty-one hours after she was centrifuged or thirty-three and one-half hours after the first lot were deposited. No effects of centrifugal force could be discovered in sections of these eggs. Normal larvæ hatched from those eggs which were not preserved.

\section{Series L.D. o}

A third batch of eggs were laid by the beetle of L.D. $f$ at I p.m. July 20. The preserved eggs showed no effects of centrifugal force; the others hatched in six days.

\section{Series L. D. $q$}

A fourth lot of eggs were laid by the same beetle as in L.D. $f$ on July 22. These agreed in every respect with those described in Series L.D. $m$.

\section{REVIEW OF THE EFFECTS OF CENTRIFUGAL FORCE UPON DEVELOPING EGGS}

\section{$I$ Distribution of the Egg Contents}

The most noticeable result obtained by centrifugal force is the redistribution of the materials contained in the egg because of the differences in their specific gravities. A number of cases have been reported of eggs whose contents are normally visibly different and localized in particular regions. For example, Boveri ('o I, $a$, p. I45, Fig. I, and 'OI, $b$, Taf. 48 and 49, Figs. 6-22) found three horizontal zones present in both unfertilized and fertilized eggs of Strongylocentrotus lividus. These zones could still be recognized in young blastulæ. Wilson ('o4, p. 68) states that, "The Dentalium egg shows from the beginning three horizontal zones, an equatorial pigment-zone and two white polar areas. Each of the 
polar areas includes a specially modified protoplasmic area probably comparable to a polar ring." Conklin ('05, $a$, p. 21 I) says of the Ascidian egg (Cynthia): "All the principal organs of the larva in their definite positions and proportions are here marked out in the 2-cell stage by distinct kinds of protoplasm," and again on p. 216 this author states that "the substances of the ectoderm, mesoderm and endoderm are recognizable in the unsegmented egg." In another place (Conklin ' $05, b$, p. 220) we find the statement that, "Three of these substances are clearly distinguishable in the ovarian egg and I do not doubt that even at this stage they are differentiated for particular ends."

Many other eggs that do not exhibit a normal stratification and are apparently homogeneous throughout take on a zone-like appearance under the influence of a strong centrifugal force. Morgan ('o6) found that when the unsegmented eggs of Rana sylvatica are revolved 1600 times per minute for seven minutes the pigment and yolk are driven to the top of the egg, leaving a clear polar field. Similar results were obtained in toads' eggs in three minutes. Lyon ('o6, '०7) was able to induce four layers in the egg of the sea-urchin, Arbacia. Two layers were obtained in eggs of the starfish, Asterias (Lyon, '07). The annelid, Chætopterus, exhibited three layers. The same author also centrifuged the eggs of the Ascidian, Cynthia, the Gephyrean, Phascolosoma, and the common garden spider; the eggs of Cynthia and Phascolosoma were stratified into three layers, those of the spider into two. Lillie ('o6) found that not only in the unsegmented eggs of Chætopterus but also in the two, four and eight celled stages three zones appeared in each cell when placed under the influence of centrifugal force. The contents of the egg of the mollusk, Cumingia, may be separated into three zones (Morgan, 'o8).

The eggs of the rotifer Hydatina senta were centrifuged by Whitney ('og) while still within the mother. Three distinct layers resulted : a pink zone, a clear middle zone and a gray zone.

The eggs of Calligrapha bigsbyana are when laid of a nearly uniform pale-yellow color. When subjected to a strong centrifugal force for a sufficient length of time three zones are distin- 
guishable: (I) a bright-orange light zone at the inner end (the vesicular zone, Fig. 20, v. z), (2) a comparatively large central mass composed of yolk globules which are largest at the outer heavy end, gradually becoming smaller until indistinguishable from cytoplasm at the inner end, and (3) a colorless layer (the gray cap, Fig. 20, g. c) at the extreme heavy end. These three zones are produced when the eggs are oriented either with their posterior (C.B. $4, e$ ) or their anterior (C.B. 3, b) ends toward the axis of rotation. When placed with their sides toward the center only two layers are induced, the vesicular zone and the yolk zone. Three layers may be obtained in fresh eggs (C.B. $4, e$ ) in eggs which have reached a late cleavage stage (C.B. 2, $b$, Fig. 18) and in eggs which are covered by a blastoderm (C.B. 5, $a$, Fig. 19).

The gray cap. The material of the gray cap is the heaviest of the egg contents. It is composed of very fine granules whose positions before being driven to the heavy end of the eggs could not be determined A fresh egg when centrifuged for one hour does not exhibit this layer (C.B. 4, $d$, Fig. IO). At the end of two hours, however, a distinct gray cap is present (C.B. $4, e$ ). Eggs in late cleavage stages require a lesser amount of centrifugal force in order to produce this structure (C.B. 2, b, Fig. I8). We conclude from this that either the gray cap material is liberated during development and the egg fourteen hours old (C.B. 2, b) contains a greater quantity of it, or else some condition of the yolk mass at this age allows it to pass more rapidly toward the heavier end. Longitudinal sections through egg C.B. 2, $c$ (Fig. 7) show that although the embryo has developed normally the material of the gray cap is still at the heavy end where it was driven by the centrifugal force. A like condition also exists in a slightly younger egg (C.B. 5, c). It is evident that the gray cap substance is not necessary for the normal development of the embryo.

$T$ The vesicular zone. The light fats which probably produce the vesicular zone at the inner end of the egg collect very quickly under the influence of centrifugal force. An egg centrifuged for only fifteen minutes (C.B. $4, b$ ) has a small number of vesicular spaces near the pole-disc. Continued application of centrifugal force results in a greater number of these vesicles until at the end of 
one hour a very distinct zone may be recognized (C.B. 4, $d$, Fig. 10). The surface of the egg in this region is in every case wrinkled and folded as though the volume had decreased at this end and the firm layer of "Keimhautblastem" had become pulled in (C.B. 4, d, Fig. Io; C.B. 4, f, Fig. I3; C.B. 1o, c, Fig. I4; C.B. 5, a, Fig. 19). This may, however, be due to poor fixation, as these folds are not visible in the eggs before they are killed.

The vesicular zone is present as such for some time after the eggs are taken from the centrifugal machine. It is not visible in sections through eggs C.B. 2, $c$, and C.B. 5, $c$, which carry normal embryos, but is present in C.B. $9, d$ (Fig. I6), which has produced a shapeless mass of tissue at the inner (anterior) end. This would indicate that the material of which this region is composed is required for normal development. However, I do not believe that this is established by the few cases observed.

The yolk zone. A very slight amount of centrifugal force is necessary to cause a noticeable disturbance in the large central yolk mass. The largest yolk spheres, as shown in C.B. $4, b$, are thrown to the outer heavy end within fifteen minutes after the egg is centrifuged. A more marked distribution of yolk globules results from a longer application of centrifugal force. A redistribution takes place very quickly after the eggs are removed from the machine; this is shown distinctly in sections through eggs C.B. 2, c, and C.B. 5, c. No redistribution took place in eggs revolved at a slow rate of speed for a long period; the yolk remained at the heavy end in these cases and the embryos, failing to grow around it, became dwarfed as shown in Figs. 21, 22 and 23. The yolk has been shown to be the densest substance in the eggs of other animals; for example, in the frog's egg the white yolk is the heaviest material, as Born ('85) proved by sectioning those that had been rotated.

The cytoplasm. The peripheral layer of cytoplasm is lighter than the gray cap material or the yolk; continued application of centrifugal force causes it to rise to the inner end of the egg (C.B. 4, $d$, Fig. Io), where it becomes part of the vesicular zone. The cytoplasm filling the interdeutoplasmic spaces also accumulates in this region. 
The cytoplasm of the beetle's egg is not made incapable of development by centrifugal force, since an embryo may be produced after a profound change in its arrangement. Gurwitsch ('O4, 'O5) concludes, from his experiments upon the eggs of amphibians and echinoderms, that no vital structure of the cytoplasm is destroyed by the forcible passage of yolk granules through it. Morgan's conclusions from his experiments with the eggs of Rana palustris are, on the contrary ('02, p. 306), that "The most important effect, however, of a strong centrifugal force is the direct injury to the protoplasm of the lower hemisphere of the egg."

The nuclei. In C.B. $4, d$ (Fig. Io) one nucleus was found near the inner end of the egg. The nuclei of eggs which are in late cleavage stages rise toward the lighter pole (compare Figs. I 7 and I8). In later stages the nuclei of the blastoderm are not affected, but the vitellophags move through the yolk toward the inner end. In every case the nucleus with its amœboid accumulation of cytoplasm moves as a whole, the nucleus remaining approximately in the center of the cytoplasmic mass. Lyon ('o6) found that the nucleus in the egg of the sea-urchin, Arbacia, is less dense than most of the other constituents. In centrifuged eggs of Asterias and Phascolosoma the nucleus is next to the lightest substance (Lyon '07); this is also the case in Hydatina senta (Whitney 'o9, p. 135). In Paramecium caudatum the nucleus is heavier than the endosarc and is driven to the outer end by the centrifugal force (McClendon 'o8). Similarly Andrews ('03) has found that in seeds the nucleus is always of higher specific gravity than the cytoplasm, cell sap and oil drops.

When the membrane dissolves the nuclear sap escapes, leaving the heavier chromatin behind. Thus we find that the spindle does not rise toward the lighter end of the egg. Lillie ('o6, p. I79) found in Chætopterus that the maturation figure is not moved by centrifugal force, but is usually fixed at the periphery. Sometimes, however, it was torn loose (p. I84), when it moves as a whole, the chromosomes and spindle never being separated by the centrifugal force. The same is true of Hydatina senta (Whitney 'o9, p. 155). Morgan ('०8, p. 446) makes the following statement after a study of the effects of centrifugal force upon the eggs 
of the mollusk, Cumingia: "In general, a resting nucleus may be forced to the lighter pole of the cell owing to the presence in the nucleus of nuclear sap, but the chromosomes and the spindle are more difficult to move, since they have nearly the same specific gravity as cytoplasm. When they move they do so as a whole, which shows that the spindle figure when present is a definite structure."

It is seldom that mitotic figures are found in sections of beetles' eggs and none was present in any of the many centrifuged eggs that I have examined. The nucleoli of the centrifuged eggs of Chrysomelid beetles seemed not to be affected, but were found in all parts of the nuclei irrespective of the direction of the centrifugal force. The nucleolus is heavier than the nuclear sap in the ova of the lobster. Its eccentric position was noted by Bumpus ('9I, p. 225); later Herrick ('95, p. 155) proved that it falls to the lower side of the nucleus "like a shot within a tennis ball." Lyon ('07, p. 168) reports that the germinal vesicle is forced to the light end when unmatured eggs of Asterias are centrifuged, but that the nucleolus is heavier.

The germ-cell determinants. Figs. II, I2 and $\mathrm{I} 3$ are from longitudinal sections through the posterior ends of eggs which had been centrifuged one hour, two hours and four hours respectively. They show that the pole-disc moves en masse toward the heavy end of the egg and that it carries with it the "Keimhautblastem" in which it is suspended. In Fig. II there is a slight indentation in the surface at the posterior end; in Fig. 12 the poledisc has penetrated farther into the yolk, leaving an open pathway $(p t)$ behind it. This pathway is really unbroken, but appears cut across in the figure. A third stage is shown in Fig. 13, where the pathway has become closed and the group of germ-cell determinants is on its way toward the anterior pole. The eggs (Series C.B. 4) were oriented with their posterier ends toward the axis of rotation. No definite conclusion could be reached concerning the comparative specific gravity of the pole-disc, but a section through an egg centrifuged with its anterior end toward the center (C.B. $3, b$ ) leaves little doubt that it lies between that of the gray cap and the yolk. The fact that the pole-disc moves as a whole, 
likewise the vitellophags, seems to show that, contrary to what Lillie ('og) finds to be the case in annelid eggs, there is here good evidence of mass movements of protoplasmic areas.

\section{The Restitution of the Egg Substances After Centrifuging}

The results obtained by several investigators from experiments with centrifugal force upon the eggs of a number of species of animals seem to prove that, as Conklin has recently stated ('o8, p. 94), "when different substances of the egg are displaced by strong centrifuging they tend to come back to their normal positions unless prevented by partition walls which have formed in the mean time."

Morgan ('o6) found that the pigment of the toad's egg does not return to its original position after the removal of the egg from the centrifugal machine. In Arbacia if the centrifuged eggs are left unfertilized readjustment begins and the eggs appear nearly normal after several hours (Lyon 'o7, p. I63). In fertilized eggs of Arbacia, Morgan and Lyon ('o7, p. I 57) claim that the materials displaced by centrifugal force do not become rearranged to any extent before cleavage begins. In Cumingia the induced distribution of the egg contents is to a large extent retained (Morgan 'o8). Very little redistribution of the egg materials takes place before the first cleavage in Hydatina senta (Whitney 'o9, p. r35). The nuclei of Paramecium caudatum, as reported by McClendon ('o8), slowly regain their normal positions after removal from the centrifugal machine; in some cases this took several generations. Andrews ('o3) states that the contents of centrifuged seeds gradually return to their original arrangement, but if kept dry this process may take several months.

There are no cell walls in the eggs of beetles when in the process of cleavage to hinder the rearrangement of materials that have been driven out of their normal positions by centrifugal force. Nevertheless readjustment takes place very slowly if at all. The yolk globules which are the first to become displaced are also the first to redistribute themselves, and we find them occupying their usual positions twenty-seven hours after the end of the experiment (C.B. 5, c). The substance of the gray cap does not become rearranged. The vesicular zone in some cases disappears in a 
short time (C.B. 5, $c$, and C.B. 2, c); in other cases it is still present after sixty-five hours (C.B. 9, d, Fig. I6). The cytoplasm undergoes a partial restitution, but in those cases where most of it has accumulated in the inner region the embryo is formed at this place (Figs. 16, 21, 22 and 23).

\section{The Age of the Egg when. Centrifuged}

The general statement may be made that the older the egg the more chances there are of its normal development after centrifuging. Morgan ('02, p. 265) states that the eggs of frogs "which have divided once or twice will withstand a greater rate of revolution than those that have not divided. Moreover, eggs that have segmented a number of times, so that the content is divided by cell walls, will develop normally at rates of revolution that kill or produce abnormalities in unsegmented eggs, or eggs just beginning to segment." The age of the egg also determines to a certain extent the amount of stratification. In the eggs of Chrtopterus (Lillie 'o6, p. 184) the stratification is not so pronounced before the breaking down of the germinal vesicle and there is no gray cap formed. Lyon ('o7, p. 168) could not distinguish any layers in unmatured eggs of Asterias.

The beetle's egg becomes stratified more quickly if centrifuged when in a late cleavage stage than when fresh (compare C.B. 4 , $d$, Fig. I0, and C.B. 2, $b$, Fig. I8). Eggs that have reached the blastoderm stage are more difficult to influence (C.B. 5, a, Fig. 19). The experiments described in this paper show that eggs in the blastoderm stage or older almost always produce normal embryos and some times larvæ (C.B. 2, c; C.B. 2, $d$; C.B. 5, c; C.B. 5 , d; C.L. $h$, 3 ; C.L. $s$, 2 ; C.L.k. 2; L.D.k. 5 ; L.D. $n$, 6 ; L.D. $n, 7)$.

\section{The Rate of Development}

The effect of agitation upon the rate of development is not certain because in several of the experiments reported the temperature was not carefuily regulated. Meltzer ('o3, p. 250) siates that the eggs of the sea-urchin, Arbacia, develop into an advanced cleavage stage more quickly than normally if they are violently 
shaken. Some experiments by Morgan ('04, p. 96) upon the toad's egg seem to show that agitation hastens the development. Whitney ('o6, p. 47) finds that "mechanical shocks and vibrations are not effective in accelerating the early segmentation of the fertilized eggs of Arbacia, Asterias, Fundulus and Ctenolabrus." The development of the eggs of Hydrophilus aterrimus is retarded if their position is reversed with respect to gravity (Megušar 'o7). The sea-urchin egg develops more slowly than is normal after being centrifuged; this is probably due to the resistance to cleavage offered by the cap and pigment (Lyon 'o7, p. r66). McClendon ('o8) found the rate of division of centrifuged Paramecia to be greater than that of normal animals. When seeds are centrifuged and restitution is slow the growth is retarded (Andrews 'o3).

Centrifugal force seems to have no influence upon the rate of development of those beetles' eggs that produced normal embryos and larvæ. A large number of observations give the average period for the development of the eggs of C. multipunctata, C. bigysbyana and C. lunata as five and two-thirds days (Hegner 'o8, a). In a great many cases normal eggs do not hatch under six and one-half days. Practically all of the centrifuged beetles' eggs hatched in six days.

\section{Eggs Centrifuged Before Deposition}

In the majority of cases the eggs laid by centrifuged beetles show no rearrangement of material and the production of an embryo or larva is not impeded. The exceptions to this are the eggs described as Series C.B. 12; here two abnormal embryos were produced by eggs which had been centrifuged within the mother before the germinal vesicles had broken down. No definite cause can be given for this irregularity.

\section{$\mathrm{X}$ SUMMARY}

I Eggs of Chrysomelid beetles when oriented in a centrifugal machine with either their posterior or anterior ends toward the axis of rotation, and subjected to $1500-2000$ revolutions per minute for from one to twelve hours, become stratified into three layers: (I) a light vesicular zone at the inner end, (2) a heavy granular 
gray cap at the outer end, and (3) a comparatively large intermediate mass of yolk, the larger globules lying at the outer end of this layer.

2 The gray cap is induced by a lesser amount of centrifugal force in an egg containing many cleavage nuclei than in a fresh egg. Either the gray cap material is liberated during development or else some condition of the yolk mass in the older egg allows it to pass more rapidly toward the heavier end. The gray cap material is not necessary for the normal development of the embryo.

3 The vesicular zone becomes visible after fifteen minutes of centrifuging. It is composed of fat imbedded in cytoplasm. This zone disappears during development.

4 The yolk globules are distributed throughout the intermediate region of the egg; the largest spheres are at the outer heavy end. It takes very little centrifugal force to cause this rearrangement. Restitution to the normal condition takes place soon after the egg is removed from the centrifugal machine.

5 The cytoplasm is lighter than the gray cap material or the yolk, but heavier than the fat of the vesicular zone. The passage of the cytoplasm to the light end of the egg does not incapacirate it for the production of an embryo.

6 The nuclei are apparently equal in specific gravity to the cytoplasm. Cleavage nuclei and vitellophags rise to the inner end of the egg; the nuclei of the blastoderm of older eggs are not visibly influenced by centrifugal force.

7 The germ-cell determinants move en masse from their usual position at the posterior end toward the anterior end when the former is placed inward. The further history of these granules has not been traced.

8 Restitution takes place very slowly. Those substances easily displaced are also the first to redistribute themselves. The cytoplasm seldom regains its normal position, but produces a dwarf embryo outside of the yolk at the light end of the egg.

9 The age of the egg determines the susceptibility to centrifugal force and the future growth of the embryo. In general an egg in a late cleavage stage becomes stratified sooner than a 
fresh egg. Eggs centrifuged when in the blastoderm stage or older almost always produce normal embryos and sometimes larvæ.

Io Centrifugal force has no influence upon the rate of development of eggs which produce normal embryos or larvæ.

I I The orientation of the embryos produced by centrifuged eggs is not affected by centrifugal force. Dwarf embryos, however, are frequently formed at the posterior ends of the eggs; these never produce larvæ.

12 In the majority of cases the eggs laid by centrifuged beetles produce normal larvæ.

I3 The eggs of insects, although supposed by many embryologists to be the most highly organized of any animal eggs, may have their contents profoundly disturbed without preventing the production of a normal embryo. The cytoplasm and nuclei of centrifuged eggs are forced out of their usual positions, but often normal development takes place. This would indicate that a high degree of organization does not prevent the egg from adapting itself to changed conditions.

The University of Michigan.

February 19, 1909.

\section{LITERATURE}

Andrews, F. M. 'o3-Die Wirkung der Centrifugalkraft auf Pflanzen. Jahrb. wiss. Bot., Bd. 38 .

Borv, E. '85-Biologische Untersuchungen. I. Ueber den Einfluss der Schwere auf das Froschei. Arch. f. mikr. Anat., Bd. 24.

Boveri, Th. 'or, a-Ueber die Polarität des Seeigeleies. Verh, der Phys. Med. Ges. zu. Würzburg, N. F., Bd. 34 .

'or, $b$-Die Polarität von Ovocyte, Ei und Larve des Strongylocentrotus lividus. Zool. Jahrb. Abth. f. Anat. u. Ontog., Bd. I4, Heft 4.

Bumpus, H. C. ' $9 \mathrm{I}-$ The Embryology of the American Lobster. Journ. of Morph., vol. 5 .

Conklin, E. G. '05 a-Organ-forming Substances in the Eggs of Ascidians. Biol. Bull., vol. 8 .

'o5 b-Mosaic Development in Ascidian Eggs. Journ. Exp. Zoöl., vol. 2. '08-The Mechanism of Heredity. Science, N. S., vol. 27. 
Gurwitsch, A., '04-Zerstörbarkeit und Restitutionsfähigkeit des Protoplasmas des Amphibieneies. Anat. Anz. Ergänzungsheft z., Bd. 25 .

'05-Ueber die Zerstörbarkeit des Protoplasmas im Echinodermenei. Anat. Anz., Bd. 27.

Hallez, P. '86-Loi de l'orientation de l'embryon chez les insects. Compt.rend., tome I03.

Hegner, R. W. 'o8, a-Observations on the Breeding Habits of Three Chrysomelid Beetles, Calligrapha bigsbyana, C. multipunctata and C. lunata. Psyche, vol. I5.

'o8, $b$-The Effects of Removing the Germ-Cell Determinants from the Eggs of Some Chrysomelid Beetles. Biol. Bull., vol. 16.

Herrick, F. H. '95-The American Lobster: a Study of its Habits and Development. Bull. U. S. Fish. Com.

Lillie, F. R. 'o6-Observations and Experiments Concerning the Elementary Phenomena of Embryonic Development in Chætopterus. Journ. Exp. Zoöl., vol. 3.

'og-Polarity and Bilaterality of the Annelid Egg. Experiments with Centrifugal Force. Biol. Bull., vol. 16.

Lyon, E. P. 'o6-Some Results of Centrifugalizing the Eggs of Arbacia. Am. Journ. Physiol., vol. I5.

'07-Results of Centrifugalizing Eggs. I. The Specific Gravity of Eggs and the Changes in Specific Gravity Occurring During Development. II. Effects of Centrifugalizing Unfertilized Eggs on their Development. Arch. Entw'm., Bd. 23 .

McClendon, J. F. '08-The Effects of Prolonged Centrifugal Force on Paramecium. Am. Journ. Physiol., vol. 21.

Megušar, F. 'o6-Einfluss abnormaler Gravitationswirkung auf die Embryonalentwicklung bei Hydrophilus aterrimus Eschscholtz. Arch. Entw'm., Bd. 22.

Meltzer, S. J. '03-Some Observations on the Effects of Agitation upon Arbacia Eggs. Am. Journ. Physiol., vol. 9.

Morgan, T. H.-'o2 The Relation between Normal and Abnormal Development of the Embryo of the Frog as Determined by Injury to the Yolk Portion of the Egg. Arch. Entw'm., Bd. I5.

'04-The Dispensability of the Constant Action of Gravity and of a Centrifugal Force in the Development of the Toad's Egg. Anat. Anz., Bd. 25 .

'o6-The Influence of a Strong Centrifugal Force on the Frog's Egg. Arch. Entw'm., Bd. 22.

'08-The Effects of Centrifuging the Eggs of the Mollusc Cumingia. Science, N. S., vol. 27, pp. 66-67 and 446 . 
WheEler, W. M. '89-The Embryology of Blatta germanica and Doryphora decemlineata. Journ. of Morph., vol. 3 .

Whitney, D. D. 'o6-An Examination of the Effects of Mechanical Shocks and Vibrations upon the Rate of Development of Fertilized Eggs. Journ. Exp. Zoöl., vol. 3 .

'og-The Effects of a Centrifugal Force upon the Development and Sex of Parthenogenetic Eggs of Hydatina senta. Journ. Exp. Zoöl., vol. 6.

Wilson, E. B. '04-Experimental Studies in Germinal Localization. I. The Germ-Regions in the Egg of Dentalium. Journ. Exp. Zoöl., vol. I. 